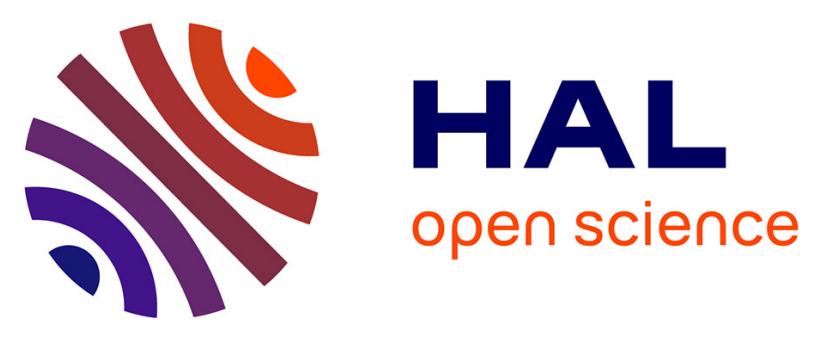

\title{
Studies of the gas phase reactions of linalool, 6-methyl-5-hepten-2-ol and 3-methyl-1-penten-3-ol with $\mathrm{O} 3$ and $\mathrm{OH}$ radicals
}

\author{
François Bernard, Véronique Daële, Abdelwahid S Mellouki, Howard
}

Sidebottom

\section{To cite this version:}

François Bernard, Véronique Daële, Abdelwahid S Mellouki, Howard Sidebottom. Studies of the gas phase reactions of linalool, 6-methyl-5-hepten-2-ol and 3-methyl-1-penten-3-ol with $\mathrm{O} 3$ and $\mathrm{OH}$ radicals. Journal of Physical Chemistry A, 2012, 116 (24), pp.6113-6126. 10.1021/jp211355d . insu02904602

\section{HAL Id: insu-02904602 \\ https://hal-insu.archives-ouvertes.fr/insu-02904602}

Submitted on 28 Jul 2020

HAL is a multi-disciplinary open access archive for the deposit and dissemination of scientific research documents, whether they are published or not. The documents may come from teaching and research institutions in France or abroad, or from public or private research centers.
L'archive ouverte pluridisciplinaire HAL, est destinée au dépôt et à la diffusion de documents scientifiques de niveau recherche, publiés ou non, émanant des établissements d'enseignement et de recherche français ou étrangers, des laboratoires publics ou privés. 


\section{Studies of the Gas Phase Reactions of Linalool, 6-Methyl-5- Hepten-2-ol and 3-Methyl-1-Penten-3-ol with $\mathrm{O}_{3}$ and $\mathrm{OH}$ Radicals}

\begin{tabular}{|c|c|}
\hline Journal: & The Journal of Physical Chemistry \\
\hline Manuscript ID: & jp-2011-11355d.R1 \\
\hline Manuscript Type: & Special Issue Article \\
\hline $\begin{array}{r}\text { Date Submitted by the } \\
\text { Author: }\end{array}$ & $n / a$ \\
\hline Complete List of Authors: & $\begin{array}{l}\text { Bernard, François; CNRS, ICARE } \\
\text { Daele, Veronique; CNRS, ICARE } \\
\text { Mellouki, Abdelwahid; CNRS, ICARE } \\
\text { Sidebottom, Howard; CNRS, ICARE }\end{array}$ \\
\hline
\end{tabular}

\section{SCHOLARONE Manuscripts}


1 Studies of the gas phase reactions of linalool, 6-methyl-5-hepten-2-ol and 32 methyl-1-penten-3-ol with $\mathrm{O}_{3}$ and $\mathrm{OH}$ radicals

3

4

5

6

\section{François Bernard, Véronique Daële, Abdelwahid Mellouki*}

7 ICARE-CNRS and OSUC, 1C Avenue de la Recherche Scientifique, 45071 cedex 02 Orléans, 8 France

9

\section{Howard Sidebottom}

10

School of Chemistry and Chemical Biology, University College Dublin, Ireland 11 12 13 14 15 16 17

18 Corresponding author 19 *Tel: +33 (0) 2382576 12. Fax: +33 (0) 2386960 04. E-mail: mellouki@ cnrs-orleans.fr 20 
2 Abstract

3 The reactions of three unsaturated alcohols (linalool, 6-methyl-5-hepten-2-ol and 3-methyl-1-

4 penten-3-ol) with ozone and $\mathrm{OH}$ radicals have been studied using simulation chambers at $\mathrm{T} \sim$

$5296 \mathrm{~K}$ and $\mathrm{P} \sim 760$ Torr. The rate coefficient values (in $\mathrm{cm}^{3}$ molecule $\mathrm{s}^{-1}$ ) determined for the

6 three compounds are: linalool, $k_{\mathrm{O} 3}=(4.1 \pm 1.0) \times 10^{-16}$ and $k_{\mathrm{OH}}=(1.7 \pm 0.3) \times 10^{-10} ; 6-$

7 methyl-5-hepten-2-ol, $k_{\mathrm{O} 3}=(3.8 \pm 1.0) \times 10^{-16}$ and $k_{\mathrm{OH}}=(1.0 \pm 0.3) \times 10^{-10} ; 3$-methyl-1-

8 penten-3-ol, $k_{\mathrm{O} 3}=(5.2 \pm 0.6) \times 10^{-18}$ and $k_{\mathrm{OH}}=(6.2 \pm 1.8) \times 10^{-11}$. From the kinetic data it is

9 estimated that for the reaction of $\mathrm{O}_{3}$ with linalool, attack at the $\mathrm{R}-\mathrm{CH}=\mathrm{C}\left(\mathrm{CH}_{3}\right)_{2}$ group

10 represents around $(93 \pm 52) \%\left(k_{6 \text {-methyl-5-hepten-2-ol }} / k_{\text {linalool }}\right)$ of the overall reaction with reaction at

11 the $\mathrm{R}-\mathrm{CH}=\mathrm{CH}_{2}$ group accounting for about $(1.3 \pm 0.5) \%\left(k_{3 \text {-methyl-1-penten-3-ol }} / k_{\text {linalool }}\right)$. In a 12 similar manner it has been calculated that for the reaction of $\mathrm{OH}$ radicals with linalool, attack 13 of the $\mathrm{OH}$ radical at the $\mathrm{R}-\mathrm{CH}=\mathrm{C}\left(\mathrm{CH}_{3}\right)_{2}$ group represents around $(59 \pm 18) \%$ ( $k_{6 \text {-methyl-5-hepten-2- }}$ 14 ol $/ k_{\text {linalool }}$ ) of the total reaction while addition of $\mathrm{OH}$ to the $\mathrm{R}-\mathrm{CH}=\mathrm{CH}_{2}$ group is estimated to be 15 around (36 \pm 6$) \%\left(k_{3-m e t h y l-1-p e n t e n-3-o l} / k_{\text {linalool }}\right)$. Analysis of the products from the reaction of $\mathrm{O}_{3}$ 16 with linalool confirmed that addition to the $\mathrm{R}-\mathrm{CH}=\mathrm{C}\left(\mathrm{CH}_{3}\right)_{2}$ group is the predominant reaction 17 pathway. The presence of formaldehyde and hydroxyacetone in the reaction products together 18 with compelling evidence for the generation of $\mathrm{OH}$ radicals in the system, indicates that the 19 hydroperoxide channel is important in the loss of the biradical $\left[\left(\mathrm{CH}_{3}\right)_{2} \mathrm{COO}\right]^{*}$ formed in the 20 reaction of $\mathrm{O}_{3}$ with linalool. Studies on the reactions of $\mathrm{O}_{3}$ with the unsaturated alcohols 21 showed that the yields of SOA are higher in the absence of $\mathrm{OH}$ scavengers compared to the 22 yields in their presence. However, even under low- $\mathrm{NO}_{\mathrm{X}}$ concentrations, the reactions of $\mathrm{OH}$ 23 radicals with 3-methyl-1-pentene-3-ol and 6-methyl-5-hepten-2-ol will make only a minor 24 contribution to SOA formation under atmospheric conditions. Relatively high yields of SOA 25 were observed in the reactions of $\mathrm{OH}$ with linalool although the initial concentrations of 
1 reactants were quite high. The importance of linalool in the formation of SOA in the

2 atmosphere requires further investigation. The impact following releases of these unsaturated 3 alcohols into the atmosphere are discussed. 


\section{1. Introduction}

2 Unsaturated alcohols have been the subject of many studies in the last two decades due to

3 their emissions in large amounts from biogenic and anthropogenic sources and their important

4 role in atmospheric chemistry. This is the case for methylbutenols (e.g. 2-methyl-3-buten-2-ol,

5 MBO232) and oxygenated monoterpenes (e.g. linalool). These compounds are highly reactive

6 towards the major atmospheric oxidants: hydroxyl radicals $(\mathrm{OH})$, ozone $\left(\mathrm{O}_{3}\right)$, nitrate radicals

$7 \quad\left(\mathrm{NO}_{3}\right)$ and chlorine atoms $(\mathrm{Cl})$, leading to very short atmospheric lifetimes (i.e. few hours or

8 less). ${ }^{1}$ These oxidation processes have been shown to produce secondary pollutants such as

9 ozone and oxygenates impacting on the tropospheric chemical composition. ${ }^{2-7}$ In order to

10 understand and assess the role of unsaturated alcohols and biogenic volatile organic

11 compounds (BVOC) in atmospheric chemistry, it is important not only to quantify their

12 emissions and atmospheric abundance but also to understand their atmospheric oxidation 13 processes.

14 In this work, the atmospheric degradation of three unsaturated alcohols has been investigated: 15 linalool (3,7-dimethylocta-1,6-dien-3-ol) $\left(\left(\mathrm{CH}_{3}\right)_{2} \mathrm{C}=\mathrm{CHCH}_{2} \mathrm{CH}_{2} \mathrm{C}(\mathrm{OH})\left(\mathrm{CH}_{3}\right) \mathrm{CH}=\mathrm{CH}_{2}\right)$, 616 methyl-5-hepten-2-ol $\left(\left(\mathrm{CH}_{3}\right)_{2} \mathrm{C}=\mathrm{CHCH}_{2} \mathrm{CH}_{2} \mathrm{CH}(\mathrm{OH}) \mathrm{CH}_{3}\right)$ and 3-methyl-1-penten-3-ol $17\left(\mathrm{CH}_{2}=\mathrm{CHC}(\mathrm{OH})\left(\mathrm{CH}_{3}\right) \mathrm{CH}_{2} \mathrm{CH}_{3}\right)$. It has been reported that linalool is emitted from vegetation, 18 especially from needles of conifer Pinus pinea ${ }^{8}$ and Pinus halepensi ${ }^{9}$ in the Mediterranean 19 area and Valencia orange blossoms. ${ }^{10}$ A mixing ratio of around $10 \mathrm{ppt}$ of linalool has been 20 reported recently at Blodgett Forest. ${ }^{11}$ 6-Methyl-5-hepten-2-ol has been detected in numerous 21 fruits, ${ }^{12,13}$ and is present in significant amounts in raspberry cultivar. ${ }^{14}$ To the best of our 22 knowledge, no biological source of 3-methyl-1-penten-3-ol has been reported, however it has 23 been used in metal nanoparticle technology for particle encapsulation. ${ }^{15}$ Investigations of the 24 mechanisms for the oxidation of 6-methyl-5-hepten-2-ol $25\left(\left(\mathbf{C H}_{3}\right)_{2} \mathbf{C}=\mathbf{C H C H}_{2} \mathbf{C H}_{2} \mathbf{C H}(\mathbf{O H}) \mathrm{CH}_{3}\right) \quad$ and 3-methyl-1-penten-3-ol 
$1 \quad\left(\mathbf{C H}_{2}=\mathbf{C H C}(\mathbf{O H})\left(\mathbf{C H}_{3}\right) \mathbf{C H}_{2} \mathrm{CH}_{3}\right)$ may also be important, since these molecules have

2 structural features in common with linalool $\left(\left(\mathrm{CH}_{3}\right)_{2} \mathrm{C}=\mathrm{CHCH}_{2} \mathrm{CH}_{2} \mathrm{C}(\mathrm{OH})\left(\mathrm{CH}_{3}\right) \mathrm{CH}=\mathrm{CH}_{2}\right)$.

3 Hence, the mechanisms for their oxidation could be useful in elucidating the reaction

4 pathways for the $\mathrm{OH}$ and $\mathrm{O}_{3}$ initiated oxidation of linalool.

5 However, no data on the oxidation of 6-methyl-5-hepten-2-ol and 3-methyl-1-penten-3-ol

6 have been reported, and a limited number of kinetic, product distribution and aerosol

7 formation studies on the reactions of $\mathrm{OH}$ and $\mathrm{O}_{3}$ with linalool have previously been

8 reported..$^{2,3,16-26}$ To our knowledge, for the $\mathrm{OH}$ reaction, no experiment has been conducted in

9 the absence of $\mathrm{NO}_{\mathrm{X}}$. The present paper reports kinetic and product studies on the reactions of $10 \mathrm{O}_{3}$ and $\mathrm{OH}$ radicals $\left(\mathrm{NO}_{\mathrm{X}}\right.$-free conditions) with linalool, 6-methyl-5-hepten-2-ol and 311 methyl-1-penten-3-ol. In addition, the yields of aerosol formation from these reactions have 12 also been determined in this work.

\section{2. Experimental methods}

15 The experiments have been performed using three atmospheric simulation chambers: the 16 EUPHORE facility (CEAM-Valencia, Spain) and two different chambers (7300 L and $200 \mathrm{~L})$ 17 at ICARE (CNRS-Orléans, France). The rate coefficients for the reactions of $\mathrm{O}_{3}$ with the three 18 compounds together with the rate coefficients for the reactions of $\mathrm{OH}$ with 3-methyl-119 penten-3-ol and 6-methyl-5-hepten-2-ol were measured using the ICARE 7300 L chamber, 20 while the $200 \mathrm{~L}$ chamber was employed for the kinetic study of $\mathrm{OH}$ with linalool. The 21 mechanistic study of the $\mathrm{O}_{3}$-initiated oxidation of 6-methyl-5-hepten-2-ol was conducted at 22 EUPHORE, while the $\mathrm{O}_{3^{-}}$and $\mathrm{OH}$-initiated oxidation of linalool and 3-methyl-1-penten-3-ol 23 were performed using the 7300 L ICARE chamber. 
1 7300L ICARE chamber. Experiments were carried out at room temperature and 760 Torr of

2 purified air $(<5 \%$ relative humidity). The chamber, made of Teflon foil, has been previously

3 described elsewhere. ${ }^{27}$ It is covered by a black opaque curtain in order to work in the dark for

4 ozone reaction studies and is equipped with 14 lamps with a wavelength of $254 \mathrm{~nm}$ in order to

5 perform OH-initiated reaction experiments (UV-A T-40 L, 40W, Viber Lourmat). Rapid

6 mixing of reactants was ensured with two fans made of Teflon during all the experimental

7 runs. After each experiment, the chamber was flushed with purified air (flow of around $100 \mathrm{~L}$

$8 \mathrm{~min}^{-1}$ ) in order to purge the remaining chemicals from the system. For the introduction of

9 compounds in the liquid state at room temperature, a known volume of reactant was

10 introduced into an impinger (gently heated when necessary) and further driven into the

11 chamber by a stream of purified air. Gaseous compounds were introduced using a calibrated

12 cylinder (0.9 L) connected to two pressure sensors (0-10 Torr and 0-100 Torr, MKS Baratron).

13 Reactants were monitored using an in situ Fourier Transform Infra Red spectrometer (FT-IR,

14 Nicolet 5700 Magna), coupled to a White-type mirror system (optical paths: 129 and $148 \mathrm{~m}$ ).

15 The instrument is operated in the mid-IR region (4000 to $650 \mathrm{~cm}^{-1}$ ). Spectra have been 16 recorded by co-adding 130 interferograms within 5 minutes at a resolution $1 \mathrm{~cm}^{-1}$. The 17 alcohols and reference compounds concentrations were determined using calibrated reference 18 spectra. Temperature and relative humidity data are recorded by a combined sensor. Ozone 19 was generated using an electric discharge on a flow of oxygen $\left(\mathrm{O}_{2}\right.$, Air liquide), which was 20 capable of a rapid introduction of ozone into the chamber. Ozone concentration was 21 continuously measured by a monitor (Thermo Environment 49C or Horiba APOA-360) based 22 on its ultraviolet absorption at $254 \mathrm{~nm}$. A measurement point was obtained at least every 10 23 seconds. Secondary Organic Aerosols (SOA), formed in the reactions of ozone and $\mathrm{OH}$ 24 radicals with the unsaturated alcohols, were also monitored over the course of the reactions 25 using a scanning mobility particle sizer (SMPS, Model TSI 3080). The SMPS consists of a 
1 Differential Mobility Analyser (DMA, Model TSI 3081) and Condensation Nuclei Counter

2 (CNC, Model TSI 3022). The sample flow was fixed at $0.2 \mathrm{~L} \mathrm{~min}^{-1}$, and the size distribution

3 of the particles formed was monitored during all the experiments. The particle size diameter

4 ranged from 20 to $1000 \mathrm{~nm}$ and was acquired every 5 minutes. Measurements started around

5 one hour before each experiment in order to characterize particle background in the chamber.

6 Statistical correction for multiple charges was applied to the measured size distribution. The 7 density of particles was assumed to be $1 \mathrm{~g} \mathrm{~cm}^{-3}$.

8 200L ICARE chamber. The 200 L FEP Teflon chamber was surrounded by six lamps 9 (Sylvania, G30W) with irradiation centred at $254 \mathrm{~nm}$. The chamber was suspended in a 10 wooden box with internal faces covered by aluminium foil. Reactants were introduced into 11 the Teflon bag by streaming purified air through a calibrated bulb (579 $\mathrm{mL})$. Hydrogen 12 peroxide was used as the source of $\mathrm{OH}$ radicals, and introduced by liquid injection into a 13 stream of purified air flowing directly into the chamber. A Gas Chromatograph, coupled to a 14 Flame Ionisation Detector (GC-FID, Star $3600 \mathrm{CX}$, Varian), was used to determine the 15 concentration of reactants in the chamber. Chromatographic separations were performed with 16 a DB-1 capillary column (J\&W Scientific, $30 \mathrm{~m}, 0.32 \mathrm{~mm}, 5 \mu \mathrm{m}$ film) operated at various 17 temperatures from $353 \mathrm{~K}$ to $508 \mathrm{~K}$.

18 EUPHORE Chamber. Gas phase product investigations of the ozonolysis of 6-methyl-519 hepten-2-ol were performed at the EUropean PHOtoREactor (EUPHORE), the large outdoor 20 simulation chamber in Valencia, Spain. A detailed description of the EUPHORE facility can 21 be found elsewhere. ${ }^{28-31}$ It consists of an approximately $200 \mathrm{~m}^{3}$ hemispherical chamber made 22 of FEP Teflon. Two fans are interfaced into the chamber which ensure homogeneous mixing 23 of the air. The chamber is equipped with an in situ FT-IR spectrometer (Magna 550) coupled 24 to a White-type mirror system with an optical path of $553.5 \mathrm{~m}$. Infra-red spectra were 25 recorded every 5 minutes co-adding 280 spectra with a resolution of $1 \mathrm{~cm}^{-1}$. The reactant and 
1 gas phase products were also monitored by gas chromatography using several different

2 detectors (photo-ionisation detector (PID), electron capture detector (ECD) and mass

3 spectrometer detector (SM)). Carbonyl compounds were sampled on DNPH-cartridges and

4 the derivatives were analysed by HPLC-UV. Ozone was measured using a monitor employing

5 UV absorption. Particle formation was monitored by a scanning mobility particle sizer (SMPS)

6 and a tapered elemental oscillating microbalance (TEOM).

7

8 While the $\mathrm{OH}$ reaction rate coefficients have been determined only by the relative rate method,

9 those for the reactions of ozone were measured using both relative and absolute rate methods.

10 In a conventional relative rate method, the values of the rate coefficients are determined by

11 following the parallel decays of the alcohols and the organic reference compounds. Loss of 12 the alcohols and the reference compounds occur in the following reactions:

$$
\text { Alcohol }+\mathrm{OH} / \mathrm{O}_{3} \rightarrow \text { Products }
$$

$k_{\text {Alcohol }}$

Reference $+\mathrm{OH} / \mathrm{O}_{3} \rightarrow$ Products

$k_{\text {Ref }}$

$15 k_{\text {Alcohol }}$ and $k_{\text {Ref }}$ are the rate coefficients of the reactions of $\mathrm{OH}$ and ozone with the studied 16 alcohols and reference compounds. Assuming that the unsaturated alcohols and reference 17 organic compounds are removed only by reaction with $\mathrm{OH}$ or ozone and by dilution processes, 18 then, it can be shown that:

19

where $[\text { Alcohol }]_{0},[\operatorname{Ref}]_{0},[\text { Alcohol }]_{\mathrm{t}}$ and $[\text { Ref }]_{\mathrm{t}}$ are the concentrations (in molecule $\mathrm{cm}^{-3}$ ) of the unsaturated alcohol and the reference organic compound at times $t_{0}$ and $t$, respectively. $k_{\text {Alcohol }}$ and $k_{\text {ref }}$ are the rate coefficients for the reactions of $\mathrm{OH}$ radicals or ozone with the unsaturated alcohol and reference compound, respectively. To take into account decay of 
1 substrate and reference compounds due to dilution and wall loss (no photolysis of these

2 compounds was observed under our experimental conditions), the terms $k_{\mathrm{L}}$ (Alcohol) and

$3 k_{\mathrm{L}}(\mathrm{Ref})$ are introduced into the equation. These terms were determined from the pseudo-first

4 order decay of the alcohol and reference compounds in the absence of any oxidants. The

5 quoted error attributed to the determined rate coefficient $k_{\text {Alcohol }}$ results from one-standard

6 deviation $(1 \sigma)$ from the slope of the plot of $\ln \left([\text { Alcohol }]_{0} /[\text { Alcohol }]_{\mathrm{t}}\right)-k_{\mathrm{L}}($ Alcohol $) \times \mathrm{t}$ against

$\left.7 \ln \left([\operatorname{Ref}]_{0} /[\operatorname{Ref}]_{\mathrm{t}}\right)-k_{\mathrm{L}}(\operatorname{Ref}) \times \mathrm{t}\right)$ and the uncertainty in the rate coefficient of the reference

8 compound. Butyl vinyl ether, isoprene, cyclohexene, 3-methyl-3-buten-1-ol and propene were

9 selected as reference organic compounds. In the study using the $7300 \mathrm{~L}$ chamber, the

10 reference compounds were monitored by FT-IR spectroscopy over the following wavenumber 11 ranges: cyclohexene, 3054-3013 $\mathrm{cm}^{-1}$; propene, 966-872 $\mathrm{cm}^{-1}$; butyl vinyl ether, 1239-1168 $12 \mathrm{~cm}^{-1}$; 3-methyl-3-buten-1-ol, 3118-3055 $\mathrm{cm}^{-1}$.

In the absolute kinetic studies of the reactions of ozone with unsaturated alcohols, the concentrations of alcohols were in excess over those of ozone, typically $[\text { Alcohol }]_{0}=(1.35-$ $12.8) \times 10^{13}$ and $[\text { Ozone }]_{0}=(0.69-13.9) \times 10^{12}\left(\right.$ in molecule $\left.\mathrm{cm}^{-3}\right)$. Under pseudo-first order conditions, ozone decay follows the following kinetic law:

$$
\left[\mathrm{O}_{3}\right]_{\mathrm{t}}=\left[\mathrm{O}_{3}\right]_{0} \mathrm{e}^{-k^{\prime} \mathrm{t}} \quad \text { where } \quad k^{\prime}=k[\text { Alcohol }]_{0}+k_{0}^{\prime}
$$

19 with $k$ representing the rate coefficient for the reaction of $\mathrm{O}_{3}$ with the three alcohols 20 investigated, and $k_{0}$ the first-order rate coefficient for $\mathrm{O}_{3}$ removal in the absence of alcohol. 21 Loss of $\mathrm{O}_{3}$ also occurs by dilution and at the wall of the chamber. By repeating the 22 experiments at different initial concentrations of alcohol, a plot of the pseudo-first order rate 23 coefficient $\left(k^{\prime}-k_{0}^{\prime}\right)$ versus initial alcohol concentration [Alcohol $]_{0}$ was obtained. The slope of 24 the plot gives the rate coefficient for the reaction of $\mathrm{O}_{3}$ with the alcohol $k$. The quoted error in 25 the obtained rate coefficient corresponds to one-standard deviation $(1 \sigma)$ from the slope. 
2 Production of aerosols was observed from the reaction of unsaturated alcohols with

3 both ozone and $\mathrm{OH}$ radicals. Experiments were carried out at room temperature and a relative

4 humidity $<5 \%$. SOA mass yields were estimated from the particle volumetric yields

5 assuming an aerosol density of $1 \mathrm{~g} \mathrm{~cm}^{-3}$. The residual particle concentration prior to the start

6 of the reactions was also measured $\left(\mathrm{N}<50 \mathrm{~cm}^{-3}\right.$ and $\left.M_{0}<0.1 \mu \mathrm{g} \mathrm{m}^{-3}\right)$. After nucleation, the

7 particle number slowly decreased through coagulation or/and wall loss on the Teflon film

8 chamber wall. Particle volume concentration increased over the course of the reaction and

9 decreased due to wall losses at the end of the reaction. Concentration-time profiles of the 10 aerosols were corrected for wall loss using the measured aerosol decay rates at the end of the 11 reaction. SOA mass yields $(\mathrm{Y})$ has been estimated from the formed aerosol mass 12 concentration $\left(M_{0}\right.$ in $\left.\mu \mathrm{g} \mathrm{m}^{-3}\right)$ and the consumed concentration of VOCs $\left(\Delta\left[\right.\right.$ Alcohol] in $\left.\mu \mathrm{g} \mathrm{m}^{-3}\right)$ 13 ratio:

$$
\mathrm{Y}=\frac{M_{0}}{\Delta[\text { Alcohol }]}
$$

The quoted error on the SOA mass yields originates from the uncertainties of the values of $M_{0}$ 16 and $\Delta[$ Alcohol], estimated to one-standard deviation $(1 \sigma)$.

\section{Chemicals}

19 The commercial source of chemicals used in this work and their stated purities are as follows: 20 linalool (Acros Organics and Alfa Aesar, 97\%), 6-methyl-5-hepten-2-ol (98\%, Alfa Aesar), 321 methyl-1-penten-3-ol (98\%, Alfa Aesar), propene (99.5\%, Air Liquide), cyclohexene ( $\geq$ $2299.5 \%$, Fluka), butyl vinyl ether (98\%, Sigma Aldrich), 3-methyl-3-buten-1-ol (97\%, Sigma 23 Aldrich), propyl vinyl ether (99\%, Sigma Aldrich), hydrogen peroxide solution (50\% in water, 
1 Sigma Aldrich), cyclohexane ( $\geq 99.5 \%$, Sigma Aldrich) and di- $n$-butylether ( $\geq 99 \%$, Sigma

2 Aldrich).

\section{Results and discussion}

5

\subsection{Reaction with ozone}

Kinetic measurements. Examples of pseudo-first order decays of ozone as a function of reaction time for different concentrations of linalool are given in Figure 1. The reaction rate coefficients were derived from the least square data fits of plots of $\left(k^{\prime}-k_{0}^{\prime}\right)$ against ([Alcohol $\left.]_{0}\right)$. Figures 2(a-c) display plots of $\left(k^{\prime}-k_{0}^{\prime}\right)$ versus the alcohol concentrations for the reactions of ozone with linalool, 6-methyl-5-hepten-2-ol and 3-methyl-1-penten-3-ol, respectively. To avoid any complications due to the generation of $\mathrm{OH}$ radicals in the chemical system, most runs were conducted in the presence of an $\mathrm{OH}$ scavenger: cyclohexane $(7.8 \times$ $10^{15}$ molecule $\mathrm{cm}^{-3}$ ) for 6-methyl-5-hepten-2-ol and 3-methyl-1-penten-3-ol, and di- $n$ butylether $\left((1.2-2.4) \times 10^{15}\right.$ molecule $\left.\mathrm{cm}^{-3}\right)$ for linalool. The rate coefficients for the reactions of cyclohexane and di- $n$-butylether with $\mathrm{OH}$ radicals are $k=(6.97 \pm 1.39) \times 10^{-12}$ $\mathrm{cm}^{3}$ molecule $\mathrm{s}^{-1},{ }^{32}$ and $k=(2.80 \pm 0.42) \times 10^{-11} \mathrm{~cm}^{3}$ molecule ${ }^{-1} \mathrm{~s}^{-1},{ }^{1}$ at $298 \mathrm{~K}$, respectively. During the absolute rate method experiments, the ozone monitor initially showed slight negative interferences in the presence of linalool and 6-methyl-5-hepten-2-ol. In these experiments, injection of ozone was performed when the ozone monitor signal was stable, typically 15 minutes after the introduction of the alcohol. Due to the low vapour pressure of unsaturated alcohols, ozone was introduced after the compound. Therefore, the ozone leakage first order rate coefficient was determined in a series of separate experiments. The average rate coefficient for ozone loss was $k_{0}=(2.5 \pm 0.2) \times 10^{-5} \mathrm{~s}^{-1}$. The rate coefficients (in $\mathrm{cm}^{3}$ molecule $\mathrm{s}^{-1}$ ) obtained for the reactions of $\mathrm{O}_{3}$ with the three alcohols at $296 \pm 3 \mathrm{~K}$ in 760 Torr of purified air are as follows: 
$1 \quad$ linalool $+\mathrm{O}_{3} \rightarrow$ Products

$$
\begin{aligned}
& k=(4.1 \pm 0.4) \times 10^{-16} \\
& k=(3.8 \pm 0.6) \times 10^{-16}
\end{aligned}
$$

2 6-methyl-5-hepten-2-ol $+\mathrm{O}_{3} \rightarrow$ Products

3 3-methyl-1-penten-3-ol $+\mathrm{O}_{3} \rightarrow$ Products

4 Additional experiments have been performed using the relative rate method. Propene was

5 used as the reference for the reaction of 3-methyl-1-penten-3-ol with ozone, and butyl vinyl

6 ether and propyl vinyl ether for the ozonolysis of linalool and 6-methyl-5-hepten-2-ol.

7 Cyclohexane was added to the gas mixtures in sufficient concentration to scavenge more than

$890 \%$ of the $\mathrm{OH}$ radicals potentially formed through the ozonolysis reactions. Preliminary

9 experiments were carried out to determine the loss of the three unsaturated alcohols and organic references in the absence of ozone. Compounds and references were introduced into 11 the chamber and their temporal behaviours were observed from 30 minutes to one hour in 12 order to assess their respective total loss rate coefficients via dilution and wall loss. Initial 13 concentrations were (in $10^{13}$ molecule $\mathrm{cm}^{-3}$ ): $[\text { Alcohol }]_{0}=1.1-7.5$ and $[\text { Reference }]_{0}=1.1-$ 14 5.8. Kinetic measurements commenced after the addition of ozone, and the parallel decays of 15 the substrates and references were monitored and quantified using FT-IR spectroscopy. The 16 duration of the runs ranged from 10 to 30 minutes for linalool and 6-methyl-5-hepten-2-ol and 17 from 20 minutes to one hour for 3-methyl-1-penten-3-ol. Plots of $\ln \left([\text { Alcohol }]_{0} /[\text { Alcohol }]_{t}\right)$ $18 k_{\mathrm{L}}(\mathrm{Alcohol}) \times \mathrm{t}$ versus $\left(\ln \left([\operatorname{Ref}]_{0} /[\operatorname{Ref}]_{\mathrm{t}}\right)-k_{\mathrm{L}}(\operatorname{Ref}) \times \mathrm{t}\right)$ were linear with slopes of $k_{\text {Alcohol }} / k_{\text {Ref. }}$ as 19 shown in Figures 3(a-c). The initial conditions and results are listed in the Table 1. Rate 20 coefficients have been calculated using the following values for the reference compounds (in $21 \mathrm{~cm}^{3}$ molecule $\left.\mathrm{s}^{-1}\right): k\left(\right.$ propene $\left.+\mathrm{O}_{3}\right)=(1.0 \pm 0.1) \times 10^{-17},{ }^{33} k\left(\right.$ propyl vinyl ether $\left.+\mathrm{O}_{3}\right)=(2.4 \pm$ $220.4) \times 10^{-16}$ and $k$ (butyl vinyl ether $\left.+\mathrm{O}_{3}\right)=(2.9 \pm 0.2) \times 10^{-16} \cdot{ }^{34}$ The rate coefficients 23 determined (in $\mathrm{cm}^{3}$ molecule $\mathrm{s}^{-1}$ ) for the three unsaturated alcohols are:

24 linalool $+\mathrm{O}_{3} \rightarrow$ Products

$$
\begin{aligned}
& k=(4.1 \pm 1.0) \times 10^{-16} \\
& k=(3.7 \pm 1.2) \times 10^{-16}
\end{aligned}
$$


1 3-methyl-1-penten-3-ol $+\mathrm{O}_{3} \rightarrow$ Products

$$
k=(5.0 \pm 0.6) \times 10^{-18}
$$

2 These rate coefficients values are in good agreement with those derived from the absolute rate

3 technique. Therefore, we recommend the average values of the rate coefficients obtained from

4 both relative and absolute rate studies (in $\mathrm{cm}^{3}$ molecule $\mathrm{s}^{-1}$ ):

$5 \quad$ linalool $+\mathrm{O}_{3} \rightarrow$ Products

6 6-methyl-5-hepten-2-ol $+\mathrm{O}_{3} \rightarrow$ Products

7 3-methyl-1-penten-3-ol $+\mathrm{O}_{3} \rightarrow$ Products

$$
\begin{aligned}
& k=(4.1 \pm 1.0) \times 10^{-16} \\
& k=(3.8 \pm 1.2) \times 10^{-16} \\
& k=(5.2 \pm 0.6) \times 10^{-18}
\end{aligned}
$$

9 No kinetic data have been reported for the reactions of $\mathrm{O}_{3}$ with 6-methyl-5-hepten-2-ol and 3methyl-1-penten-3-ol, while two previous investigations on the reaction with linalool have 11 been carried out. ${ }^{16,19}$ The rate coefficient determined by Atkinson et al. ${ }^{16}$ was obtained using 12 the relative rate method, with 2-methyl-2-butene used as the reference compound. Taking $k(2-$ 13 methyl-2-butene $\left.+\mathrm{O}_{3}\right)=4.1 \times 10^{-16} \mathrm{~cm}^{3}$ molecule $\mathrm{s}^{-1}, 33$ a value of the rate coefficient for the 14 reaction of $\mathrm{O}_{3}$ with linalool of $k=(4.5 \pm 0.1) \times 10^{-16} \mathrm{~cm}^{3}$ molecule $\mathrm{s}^{-1} \mathrm{~s}^{-1}$ was derived, which is rate of ozone decay in the system was similar to the response time of the ozone monitor.

The data obtained in the present work indicate that the rate coefficients for the reactions of 21 ozone with linalool and 6-methyl-5-hepten-2-ol are similar, while that for reaction with 3methyl-1-penten-3-ol is around two orders of magnitude lower. The high reactivity of linalool and 6-methyl-5-hepten-2-ol can be explained, at least in part, by the high degree of substitution of the double bond $\left(-\mathrm{CH}=\mathrm{C}\left(\mathrm{CH}_{3}\right)_{2}\right)$ at which the reaction with ozone is expected to proceed. As expected, the low degree of substitution of the double bond $\left(-\mathrm{CH}=\mathrm{CH}_{2}\right)$ leads 
1 to the observed reduction in reactivity of 3-methyl-1-penten-3-ol towards $\mathrm{O}_{3}$, which is in

2 agreement for the corresponding reaction with the structurally similar compound 2-methyl-3-

3 buten-3-ol $\left(\mathrm{CH}_{2}=\mathrm{CHC}\left(\mathrm{CH}_{3}\right)_{2}(\mathrm{OH})\right)$ within the stated uncertainties $\left(k=(1.0 \pm 0.6) \times 10^{-17} \mathrm{~cm}^{3}\right.$

4 molecule $\left.\mathrm{s}^{-1}\right){ }^{33}$

5 It is of interest to note that the value of the rate coefficient for the reaction of $\mathrm{O}_{3}$ with linalool

6 is close to the sum of the rate coefficients for the reactions of $\mathrm{O}_{3}$ with the other two

7 unsaturated alcohols investigated:

$$
k\left(6 \text {-methyl-5-hepten-2-ol }+\mathrm{O}_{3}\right)+k\left(3 \text {-methyl-1-penten-3-ol }+\mathrm{O}_{3}\right) \approx k\left(\text { linalool }+\mathrm{O}_{3}\right)
$$

9 The rate coefficients obtained in this work suggest that for the reaction of $\mathrm{O}_{3}$ with linalool, 10 attack at the $\mathrm{R}-\mathrm{CH}=\mathrm{C}\left(\mathrm{CH}_{3}\right)_{2}$ group represents around $(93 \pm 52) \%\left(k_{6 \text {-methyl-5-hepten-2-ol }} / k_{\text {linalool }}\right)$ of 11 the overall reaction with reaction at the $\mathrm{R}-\mathrm{CH}=\mathrm{CH}_{2}$ group accounting for about $(1.3 \pm 0.5) \%$ $12\left(k_{3-\text { methyl-1-penten-3-ol }} / k_{\text {linalool }}\right)$. Atkinson et al. ${ }^{16}$ and Shu et al. ${ }^{3}$ previously proposed that $97 \%$ of 13 the reaction with ozone proceeds by addition to the $\mathrm{R}-\mathrm{CH}=\mathrm{C}\left(\mathrm{CH}_{3}\right)_{2}$ group and only $3 \%$ to the $14 \mathrm{R}-\mathrm{CH}=\mathrm{CH}_{2}$ group in agreement with the estimates from the present study.

16 Gas phase product studies. For each unsaturated alcohol, a set of three experiments was 17 performed in the presence of cyclohexane as a scavenger for $\mathrm{OH}$ radicals. In all the 18 experiments, the alcohol was injected first into the chamber followed by the addition of 19 cyclohexane. Prior to the addition of ozone, the organic compounds were monitored for at 20 least 30 minutes. The reactant concentrations employed were in the range $(1.62-4.49) \times 10^{13}$ 21 molecule $\mathrm{cm}^{-3}$ at ICARE and (4.91 - 5.59) $\times 10^{12}$ molecule $\mathrm{cm}^{-3}$ at EUPHORE. Figure 4 22 displays IR spectra obtained from the ozonolysis of linalool at different stages of the reaction. 23 The reference spectrum of linalool is shown in panel A, while panels B and C show the IR 24 spectra of linalool and $\mathrm{O}_{3}$ at the start of the reaction and after 2 hours of reaction respectively. 25 Panels D, E, F and G display the IR reference spectra of acetone, formaldehyde, 
1 hydroxyacetone and formic acid, respectively. A typical residual IR spectrum (after

2 subtraction of the reactants and all identified products) is shown in panel $\mathrm{H}$. The derived

3 product formation yields for the reactions of ozone with the unsaturated alcohols are

4 summarized in Tables 2 (a-c).

5 Products identified from the reaction of ozone with linalool were acetone $(35 \pm 6) \%$, 6 formaldehyde $(32 \pm 6) \%$ and hydroxyacetone $(28 \pm 5) \%$. Ozonolysis of 3-methyl-1-penten-3-

7 ol gave formaldehyde and 2-butanone as the major products with formation yields of (29 \pm $84) \%$ and $(46 \pm 3) \%$, respectively. A stoichiometric ratio of $\Delta\left[\mathrm{O}_{3}\right] / \Delta[3$-methyl-1-penten-3-ol $]=$

$9 \quad 1.1 \pm 0.1$ was obtained in the absence of cyclohexane suggesting that the formation yield of

$10 \mathrm{OH}$ radicals in the system was negligible. The products identified and quantified from the 11 reaction of ozone with 6-methyl-5-hepten-2-ol were: acetone $(31 \pm 7) \%$, formaldehyde $(40 \pm$ $1210) \%$, hydroxyacetone $(17 \pm 2) \%$, formic acid $(16 \pm 4) \%$ and methylglyoxal $(10 \pm 1) \%$.

13 Formation of 4-hydroxypentanal as a product of the ozonolysis was also expected, however, a 14 sample of this compound was not commercially available and hence it could not be positively 15 quantified. The yield of 4-hydroxypentanal was tentatively quantified using 4-pentanal as a 16 surrogate, which was introduced into the gas mixture at the end of the experiment. A yield of 17 4-hydroxypentanal of around 34\% was estimated using HPLC-UV, assuming the response 18 factor for the DNPH derivatives of both 4-pentanal and 4-hydroxypentanal were the same. In 19 addition, cyclohexanone and cyclohexanol have also been identified as products by GC-MS, 20 indicating the formation of $\mathrm{OH}$ radicals in the ozonolysis reaction. ${ }^{35}$ Then, $\mathrm{OH}$ formation 21 yield from the ozonolysis of 6-methyl-5-hepten-2-ol has been derived and found to be (65 \pm $2220) \%$ which is similar to that of linalool $(66 \pm 10) \% .^{22}$

23 To date, of the unsaturated alcohols studied in this work, only the gas phase products from the 24 ozonolysis of linalool have been reported..$^{2,3,23}$ Grosjean and Grosjean ${ }^{2}$ performed experiments 25 with a relative humidity of $50 \%$, while the other studies were conducted with relative 
1 humidities below $10 \%$. The acetone yield $(35 \pm 6) \%$ obtained in this work agrees with that

2 reported by Grosjean and Grosjean ${ }^{2}(28 \pm 1) \%$ but is higher than that from Shu et al. ${ }^{3}(21.1 \pm$ $32.4) \%$ and Lee et al. ${ }^{23}(16 \pm 1) \%$. The measured yield of formaldehyde $(32 \pm 6) \%$ is in line 4 with the previously reported values by Shu et al. $^{3}(36 \pm 6) \%$ and Lee et al. ${ }^{23}(34 \pm 3) \%$. 5 Hydroxyacetone was detected as a product of the ozonolysis of linalool in this work with a 6 yield of $(28 \pm 5) \%$. This product has not previously been observed, however, Grosjean and 7 Grosjean $^{2}$ detected methylglyoxal as a reaction product with a yield of $(11 \pm 1) \%$ following 8 derivatization with DNHP. This product could not be resolved under our experimental 9 conditions, however as mentioned by Grosjean and Grosjean, ${ }^{2}$ the reaction of hydroxyacetone 10 and methylglyoxal with DNHP leads to the same derivative. Hence, it is possible that 11 hydroxyacetone may interfere in the quantification of methylglyoxal. 4-Hydroxy-4-methyl-512 hexen-1-al (or 2-ethenyl-2-methyl-5-hydroxytetrahydrofuran) has also been reported as a 13 major product from the ozonolysis of linalool with a formation yield of $(85 \pm 14) \%{ }^{3}$ and (50 $14 \pm 9) \%,{ }^{23}$ 5-Ethenyldihydro-5-methyl-2(3H)-furanone and acetaldehyde were also detected as 15 products with yields of $(12.6 \pm 2.5) \%,^{3}$ and $(14 \pm 1) \%,{ }^{23}$ respectively.

17 It is well established that the reaction of ozone with unsaturated alcohols proceeds by 18 electrophilic addition of ozone to the double bond. ${ }^{36}$ This leads to a primary ozonide, which 19 decomposes to an energy-rich Criegee biradical and the corresponding carbonyl compound. A 20 mechanistic scheme for the reaction of ozone with 3-methyl-1-penten-3-ol is shown in Figure 215 based on the observed and/or expected products. This reaction proceeds by initial addition 22 of ozone to the $\mathrm{R}-\mathrm{CH}=\mathrm{CH}_{2}$ group forming an ozonide, which then rapidly decomposes to 23 either $\mathrm{C}_{2} \mathrm{H}_{5} \mathrm{C}(\mathrm{OH})\left(\mathrm{CH}_{3}\right) \mathrm{CHO}$ (3-hydroxy-3-methyl-1-butanal) plus the $\left[\mathrm{CH}_{2} \mathrm{OO}\right]^{*}$ biradical 24 or $\mathrm{HCHO}$ plus the $\left[\mathrm{C}_{2} \mathrm{H}_{5} \mathrm{C}(\mathrm{OH})\left(\mathrm{CH}_{3}\right) \mathrm{CHOO}\right]^{*}$ biradical. The energy-rich $\left[\mathrm{CH}_{2} \mathrm{OO}\right]^{*}$ biradical, 25 can be either stabilized or decomposes to form $\mathrm{HCOOH}, \mathrm{CO}, \mathrm{CO}_{2}, \mathrm{H}_{2} \mathrm{O}, \mathrm{H}_{2}$ and the $\mathrm{OH}$ 
1 radical. ${ }^{37,38}$ The Criegee intermediate $\left[\mathrm{C}_{2} \mathrm{H}_{5} \mathrm{C}(\mathrm{OH})\left(\mathrm{CH}_{3}\right) \mathrm{CHOO}\right]^{*}$, formed through channel 2 (2), can also be either stabilized to form 3-hydroxy-3-methyl-1-butanal (channel (2a)), or 3 decomposes to form $\mathrm{CO}_{2}$ and the $\mathrm{C}_{2} \mathrm{H}_{5} \mathrm{C}(\mathrm{OH})\left(\mathrm{CH}_{3}\right)$ alkoxy radical. This radical will rapidly

4 react with $\mathrm{O}_{2}$ to form 2-butanone. Based on the observed yield of 2-butanone, the proposed 5 mechanism suggests that channel (2) accounts for at least $46 \%$ of the reaction of $\mathrm{O}_{3}$ with 36 methyl-1-penten-3-ol. Thus, it appears that decomposition of the primary ozonide in channels 7 (1) and (2) is of equivalent importance. The mechanism suggests that the yield of 8 formaldehyde should at least be the same as that for 2-butanone. However, the formaldehyde 9 formation yield was found to be only $29 \%$, which indicates that either formaldehyde is 10 removed from the system in secondary processes or there is an additional source of 211 butanone not identified in this work.

12 The available kinetic data suggest that the reactions of ozone with linalool and 6-methyl-513 hepten-2-ol occur mainly at the $\mathrm{R}-\mathrm{CH}=\mathrm{C}\left(\mathrm{CH}_{3}\right)_{2}$ double bond, and that addition at the R$14 \mathrm{CH}=\mathrm{CH}_{2}$ double bond will only represent a minor pathway. Decomposition of primary ozonides can lead either to the formation of acetone and the corresponding Criegee biradical $16\left(\mathrm{CI}_{1}\right)$ in channel 1 , or form the biradical $\left[\left(\mathrm{CH}_{3}\right)_{2} \mathrm{COO}\right]^{*}\left(\mathrm{CI}_{2}\right)$ and the carbonyl compounds 417 hydroxy-4-methyl-5-hexen-1-al and 4-hydroxypentanal from linalool and 6-methyl-5-hepten2-ol, respectively. Moreover, the observed products (formaldehyde and hyroxyacetone) and 19 the $\mathrm{OH}$ formation yields from the ozonolysis of linalool and 6-methyl-5-hepten-2-ol indicate 20 that hydroperoxide channel is an important pathway in the fate of $\left[\left(\mathrm{CH}_{3}\right)_{2} \mathrm{COO}\right]^{*}$ via the 21 formation of the $\left[\mathrm{CH}_{3} \mathrm{C}(\mathrm{OOH})=\mathrm{CH}_{2}\right]^{*}$ isomer. ${ }^{39,40}$

Aerosol formation. Under our experimental conditions, the SOA mass yields from the ozonolysis of 3-methyl-1-penten-3-ol ranged from 0 to $1.9 \%$ in the absence of $\mathrm{OH}$ scavenger and from 0.08 to $0.3 \%$ in the presence of cyclohexane. The ozonolysis of 6-methyl-5-hepten- 
12 -ol led to a SOA mass yield of around $2 \%$ in the absence of $\mathrm{OH}$ scavenger and $0.5 \%$ in the

2 presence of cyclohexane. Linalool ozonolysis experiments showed that for reactions

3 performed in the presence of cyclohexane, the SOA mass yields varied from $1.4 \%$ to $1.9 \%$,

4 while in the absence of an $\mathrm{OH}$ scavenger the SOA yield was approximately $10 \%$. The SOA

5 yields from the ozonolysis of linalool in the presence of an $\mathrm{OH}$ scavenger obtained in this

6 study are in broad agreement with that of $1 \%$ reported by Lee et al. ${ }^{23}$ In the absence of a

7 scavenger, the $10 \%$ SOA yield determined in this work is in reasonable agreement with the

8 value of $8 \%$ reported by Hoffmann et al. ${ }^{18}$, although considerably higher than the estimate of

$92 \%$ obtained by Chen et al. ${ }^{26}$ The present results show that SOA formation from the 10 ozonolysis of the unsaturated alcohols studied is relatively low. Nevertheless, in the absence 11 of $\mathrm{OH}$ scavengers the SOA mass yield is higher than in their presence, which is in agreement 12 with previous observations from studies on the ozonolysis of alkenes. ${ }^{41-43}$

\section{$14 \quad 4.2$ Reaction with $\mathbf{O H}$ radicals}

15 Kinetic measurements. $\mathrm{OH}$ radicals were generated through the photolysis of $\mathrm{H}_{2} \mathrm{O}_{2}$ at $254 \mathrm{~nm}$.

16 Preliminary experiments were performed in order to check the stability of the alcohols in the 17 presence of the reference compounds and $\mathrm{H}_{2} \mathrm{O}_{2}$ in the dark. Additional tests were carried out 18 in order to check the photostability of the organic compounds in the absence of $\mathrm{H}_{2} \mathrm{O}_{2}$. The 19 duration of the tests ranged from 30 minutes to more than one hour. The results of these 20 experiments showed that decay of the organic compounds in the absence of $\mathrm{H}_{2} \mathrm{O}_{2}$ was 21 negligible except for loss at the wall and by dilution. No loss other than the reaction with $\mathrm{OH}$ 22 radicals has been observed for linalool and the reference compounds. The experiments on 323 methyl-1-penten-3-ol and 6-methyl-5-hepten-2-ol were conducted in the $7300 \mathrm{~L}$ chamber 24 using FT-IR as the analytical tool, while the study of the reaction of linalool with OH was 25 performed in the 200L chamber using GC-FID for monitoring the decays of the organic 
1 compounds. The initial concentrations used in the $7300 \mathrm{~L}$ chamber were: $[\text { Alcohol }]_{0}=(2.6$ $24.8) \times 10^{13} ;[\text { Reference }]_{0}=(2.6-5.3) \times 10^{13} ;\left[\mathrm{H}_{2} \mathrm{O}_{2}\right]_{0}=(3-4) \times 10^{14}$ molecule $\mathrm{cm}^{-3}$. The

3 initial concentrations of reactants employed in the $200 \mathrm{~L}$ chamber for the linalool experiments

4 were (in molecule $\left.\mathrm{cm}^{-3}\right)$ : $[\text { Linalool }]_{0}=(2.0-6.6) \times 10^{14} ;[\text { Reference }]_{0}=(2.5-6.6) \times 10^{14}$; $5 \quad\left[\mathrm{H}_{2} \mathrm{O}_{2}\right]_{0}=(1-4) \times 10^{15}$. Experimental durations varied from 90 to 120 minutes. Plots of $6 \ln \left([\text { Alcohol }]_{0} /[\text { Alcohol }]_{\mathrm{t}}\right)-k_{\mathrm{L}}(\mathrm{Alcohol}) \times \mathrm{t}$ against $\left(\ln \left([\operatorname{Ref}]_{0} /[\operatorname{Ref}]_{\mathrm{t}}\right)-k_{\mathrm{L}}(\operatorname{Ref}) \times \mathrm{t}\right)$ gave good 7 straight lines, Figures 6(a-c) for linalool, 6-methyl-5-hepten-2-ol and 3-methyl-1-penten-3-ol 8 respectively, and the slopes provide values of the rate coefficient ratios $k_{\text {Alcohol }} / k_{\text {Ref. }}$. The 9 reference rate coefficients used to derive the rate coefficients for the reactions of $\mathrm{OH}$ with the 10 three unsaturated alcohols were (in $\mathrm{cm}^{3}$ molecule $\mathrm{s}^{-1}$ ): butyl vinyl ether and propyl vinyl 11 ether $\left((1.1 \pm 0.1) \times 10^{-10}, 44\right)$; isoprene $\left((1.0 \pm 0.1) \times 10^{-10}, 33\right)$; propene $\left((2.9 \pm 0.3) \times 10^{-11}, 33\right)$; 12 cyclohexene $\left.(6.8 \pm 1.7) \times 10^{-11}, 36\right)$ and 3-methyl-3-buten-1-ol $\left((9.4 \pm 0.4) \times 10^{-10},{ }^{45}\right)$.

13 The experimental conditions and the values obtained for $k_{\text {Alcohol }} / k_{\text {Ref. }}$ are listed in Table 3 . The 14 rate coefficients for the studied reactions are taken as the average of different measurements 15 leading to (at $296 \pm 4 \mathrm{~K}, 760$ Torr of purified air, and in $\mathrm{cm}^{3}$ molecule $\mathrm{s}^{-1}$ ):

16 linalool $+\mathrm{OH} \rightarrow$ Products

$$
\begin{aligned}
& k=(1.7 \pm 0.3) \times 10^{-10} \\
& k=(1.0 \pm 0.3) \times 10^{-10} \\
& k=(6.2 \pm 1.8) \times 10^{-11}
\end{aligned}
$$$$
18 \text { 3-methyl-1-penten-3-ol }+\mathrm{OH} \rightarrow \text { Products }
$$

19 The quoted errors were estimated from the least squares analysis of the relative rate data. In 20 addition, two runs were conducted in the $7300 \mathrm{~L}$ chamber (using FT-IR for analysis) to 21 measure the decay rate of linalool relative to that of 6-methyl-5-hepten-2-ol for reaction with $22 \mathrm{OH}$ radicals. The experimental result was $k($ linalool $+\mathrm{OH}) / k(6-$ methyl-5-hepten-2-ol $)=1.4 \pm$ 230.2 , which is in reasonable agreement with the rate coefficient ratios determined in 24 independent measurements $(1.7 \pm 0.8)$. 
1 In this work, we report the first measurements of the rate coefficients for reaction of $\mathrm{OH}$ with

2 3-methyl-1-penten-3-ol and 6-methyl-5-hepten-2-ol. To our knowledge, this work is the third

3 determination of the rate coefficient of the reaction of linalool with $\mathrm{OH}$ radicals. ${ }^{16,21}$ The rate

4 coefficient reported for the reaction of $\mathrm{OH}$ with linalool by Atkinson et al. ${ }^{16}$ was performed

5 using a relative rate method with isoprene as the reference compound. Based on the IUPAC

6 recommendation ${ }^{33}$ for $k(\mathrm{OH}+$ isoprene $)=(1.0 \pm 0.1) \times 10^{-10} \mathrm{~cm}^{3}$ molecule $\mathrm{s}^{-1}$, a value of

$7 k($ linalool $+\mathrm{OH})=(1.57 \pm 0.20) \times 10^{-10} \mathrm{~cm}^{3}$ molecule $\mathrm{e}^{-1} \mathrm{~s}^{-1}$ was derived from the rate data in

8 reasonable agreement with the value determined in this study. The measurement of Bernhard

9 and Simonich ${ }^{21}$ was also obtained using the relative rate method with styrene as the reference

10 compound. Taking $k(\mathrm{OH}+$ styrene $)=(5.8 \pm 1.2) \times 10^{-11} \mathrm{~cm}^{3}$ molecule $\mathrm{s}^{-1} \mathrm{~s}^{-1}$, leads to a value

$11\left(k(\right.$ linalool $+\mathrm{OH})=(2.15 \pm 0.58) \times 10^{-10} \mathrm{~cm}^{3}$ molecule $\mathrm{s}^{-1}$, which is within the stated 12 uncertainties of the rate coefficient determined in this work.

13 The rate coefficients determined for the reaction of $\mathrm{OH}$ with 3 -methyl-1-penten-3-ol $(k=(6.2$ $14 \pm 1.8) \times 10^{-11} \mathrm{~cm}^{3}$ molecule $\mathrm{s}^{-1}$ ) is around two times higher than that estimated by the SAR 15 method $\left(k=2.95 \times 10^{-11} \mathrm{~cm}^{3}\right.$ molecule $\left.{ }^{-1} \mathrm{~s}^{-1}\right) .{ }^{47,48}$ However, it is in line with the reported rate 16 coefficient for the reaction of $\mathrm{OH}$ with the structurally similar compound 2-methyl-3-buten-317 ol $\left(\mathrm{CH}_{2}=\mathrm{CHC}\left(\mathrm{CH}_{3}\right)_{2}(\mathrm{OH})\right)\left(k=6.4 \times 10^{-11} \mathrm{~cm}^{3}\right.$ molecule ${ }^{-1} \mathrm{~s}^{-1}$ at $298 \mathrm{~K}^{33}$ The measured rate 18 coefficient for the $\mathrm{OH}$ reaction with 6-methyl-5-hepten-2-ol $\left(k=(1.0 \pm 0.3) \times 10^{-10} \mathrm{~cm}^{3}\right.$ 19 molecule $\left.\mathrm{s}^{-1}\right)$ is very close that calculated from the SAR method $\left(k=9.89 \times 10^{-11} \mathrm{~cm}^{3}\right.$ 20 molecule $\mathrm{e}^{-1}$ ).

21 The kinetic data reported in this work show that (within the stated uncertainties): $k(6$-methyl-5-hepten-2-ol $+\mathrm{OH})+k(3$-methyl-1-penten-3-ol $+\mathrm{OH}) \approx k($ linalool $+\mathrm{OH})$

23 in a similar manner to that found for the $\mathrm{O}_{3}$ kinetic studies.

24 The reactions of the unsaturated alcohols with $\mathrm{OH}$ radicals proceed mainly by addition to the $25>\mathrm{C}=\mathrm{C}<$ double bond system. The kinetic data indicate that the sum of the rate coefficients for 
1 reaction of $\mathrm{OH}$ with 6-methyl-5-hepten-2-ol and 3-methyl-1-penten-3-ol are close to that for

2 reaction with linalool. Hence, the double bond in each of these molecules exhibits virtually

3 the same reactivity in linalool as they have in the individual molecules. Thus, it is possible to

4 calculate that for the reaction of $\mathrm{OH}$ radicals with linalool, attack of the $\mathrm{OH}$ radical at the R-

$5 \mathrm{CH}=\mathrm{C}\left(\mathrm{CH}_{3}\right)_{2}$ group represents around $(59 \pm 18) \%\left(k_{6-\text { methyl-5-hepten-2-ol }} / k_{\text {linalool }}\right)$ of the total

6 reaction while addition of $\mathrm{OH}$ to the $\mathrm{R}-\mathrm{CH}=\mathrm{CH}_{2}$ group is estimated to be around (36 \pm 6$) \%$

$7 \quad\left(k_{3-m e t h y l-1-p e n t e n-3-o l} / k_{\text {linalool }}\right)$. Calculations using the SAR method ${ }^{47,48}$ suggest that $\mathrm{OH}$ addition at

8 the $\mathrm{R}-\mathrm{CH}=\mathrm{C}\left(\mathrm{CH}_{3}\right)_{2}$ and $\mathrm{R}-\mathrm{CH}=\mathrm{CH}_{2}$ groups will represent $74 \%$ and $22 \%$ respectively of the 9 overall reaction.

11 Gas phase product studies. The products of the reactions of $\mathrm{OH}$ radicals with the unsaturated 12 alcohols at room temperature and 760 Torr of air were monitored using FT-IR spectroscopy. 13 The photolysis of $\mathrm{H}_{2} \mathrm{O}_{2}$ at $254 \mathrm{~nm}$ was used to generate $\mathrm{OH}$ radicals. Reaction mixtures 14 consisted of $(1.2-9.1) \times 10^{13}$ molecule $\mathrm{cm}^{-3}$ of unsaturated alcohols and $(0.32-5.7) \times 10^{14}$ 15 molecule $\mathrm{cm}^{-3}$ of $\mathrm{H}_{2} \mathrm{O}_{2}$. A set of three experiments was performed for each unsaturated 16 alcohol. The products of the reactions have been assigned using IR reference spectra when 17 available. Gas phase formation yields for the oxidation products were obtained after 18 correction of their concentration time-profiles for dilution and for loss by secondary reactions 19 with $\mathrm{OH}$ radicals. The observed products from the three unsaturated alcohols and their 20 corresponding reaction rate coefficients with $\mathrm{OH}$ (in $\mathrm{cm}^{3}$ molecule $\mathrm{s}^{-1}$ ) are the following: 21 formaldehyde $\left(8.5 \times 10^{-12}\right)$, formic acid $\left(4.5 \times 10^{-13}\right)$, carbon monoxide $\left(2.8 \times 10^{-12}\right)$, 22 glycolaldehyde $\left(8 \times 10^{-12}\right)$, 2-butanone $\left(1.2 \times 10^{-12}\right)$, methanol $\left(9 \times 10^{-13}\right)$, acetone $\left(1.8 \times 10^{-13}\right)$ 23 and 6-methyl-5-hepten-2-one $\left(1.57 \times 10^{-10}\right)$. These rate coefficient values were taken from the 24 IUPAC recommendation, ${ }^{33}$ except for 6-methyl-5-hepten-2-one, which is from Smith et al. ${ }^{49}$ 25 Corrections of concentration time-profiles of the oxidation products formed have been applied 
1 according to the formula given by Atkinson et al. ${ }^{50}$ Preliminary tests were conducted in order

2 to observe the behaviour of the unsaturated alcohols in the absence of any oxidants and

3 possible oxidation products, which might be formed. The results showed that under these

4 conditions, consumption of the unsaturated alcohols was negligible. Figure 7 shows the IR

5 spectra of linalool (Panel A), and a mixture of linalool and $\mathrm{H}_{2} \mathrm{O}_{2}$ at the start of the reaction

6 (Panel B). Panel $\mathrm{C}$ shows the IR spectrum after 4 hours reaction (linalool and $\mathrm{H}_{2} \mathrm{O}_{2}$ subtracted

7 from the IR global spectrum). The reference spectra of acetone, formic acid, glycolaldehyde

8 and 6-methyl-5-hepten-2-one are displayed in the Panels D, E, F and G, respectively. Panel H

9 shows the residual spectrum after subtraction of reactants and all identified products.

10 Due to secondary reactions, the yields of gas phase products do not scale linearly with the loss 11 of linalool over the whole experimental time. Therefore, the yields of products were obtained 12 by plotting the gas phase product concentrations versus the linalool consumption in the early 13 stages of the reaction, as shown in Figure 8. The molar product yields were derived from the 14 least-square analysis of the data and are summarized in Tables 4(a-c). The major products 15 identified from the $\mathrm{OH}-$ initiated reaction of linalool were acetone $(34 \pm 1) \%$, glycolaldehyde $16(14 \pm 1) \%$ and 6-methyl-5-hepten-2-one $(10 \pm 2) \%$. The indicated errors arise from the 17 average of yields obtained from the three individual experiments. For the reaction of $\mathrm{OH}$ with 18 6-methyl-5-hepten-2-ol, acetone was identified as the major product with a yield of $(21 \pm 2) \%$.

19 Other minor products identified in the system were formic acid $(4.2 \pm 0.7) \%$, formaldehyde $20(0.7 \pm 0.4) \%$ and carbon monoxide $(1.2 \pm 0.6) \%$. The OH-initiated oxidation of 3-methyl-121 penten-3-ol produced 2-butanone $(41 \pm 6) \%$ and glycolaldehyde $(30 \pm 4) \%$ as major products 22 with formic acid $(2.2 \pm 0.9) \%$, formaldehyde $(9 \pm 4) \%$ and carbon monoxide $(2.5 \pm 0.3) \%$ as 23 minor products.

24 A number of product studies on the $\mathrm{OH}$ radical initiated oxidation of linalool have been 25 reported, however, the previous studies were carried out in the presence of $\mathrm{NO}_{\mathrm{X}} \cdot{ }^{3,17,24}$ 
1 Therefore, this work reports for the first time the yields of products from the $\mathrm{OH}$ initiated

2 oxidation in the in the absence of $\mathrm{NO}_{\mathrm{X}}$. The $\mathrm{OH}$ initiated oxidations of 6-methyl-5-hepten-2-

3 ol and 3-methyl-1-penten-3-ol have not previously been reported.

4 The kinetic data leads to the prediction that addition of $\mathrm{OH}$ to the $\left(\mathrm{R}-\mathrm{CH}=\mathrm{C}\left(\mathrm{CH}_{3}\right)_{2}\right)$ group is 5 likely to dominate over reaction at $\left(\mathrm{R}-\mathrm{CH}=\mathrm{CH}_{2}\right)$ with a ratio of around $59 \% / 36 \%$. The 6 proposed reaction schemes following $\mathrm{OH}$ addition at the $\mathrm{R}-\mathrm{CH}=\mathrm{CH}_{2}$ and $\mathrm{R}-\mathrm{CH}=\mathrm{C}\left(\mathrm{CH}_{3}\right)_{2}$ sites 7 in linalool are shown in Figures 9a and 9b, respectively. 6-Methyl-5-hepten-2-one and 8 glycolaldehyde are expected to be formed following $\mathrm{OH}$ attack at the $=\mathrm{CH}_{2}$ position of the R-

$9 \mathrm{CH}=\mathrm{CH}_{2}$ double bond as shown in reaction channel (1) of Figure 10c. Addition of $\mathrm{OH}$ to the $\mathrm{RCH}=$ position of the double bond leads to the generation of formaldehyde and 2,6-dimethyl11 2-hydroxy-5-hepten-1-one, channel (2). The low yield of HCHO (2.8\%) indicates that $\mathrm{OH}$ 12 radical addition at the $=\mathrm{CH}_{2}$ position, channel (1), is dominant. This result is consistent with 13 the observation that addition of radical species normally occurs at the least substituted carbon 14 atom of a double bond in an alkene, and is in agreement with the low HCHO yield reported 15 previously by Shu et al. ${ }^{3}$ Addition of the $\mathrm{OH}$ radical to the $\mathrm{R}-\mathrm{CH}=\mathrm{C}\left(\mathrm{CH}_{3}\right)_{2}$ group of linalool 16 is expected to produce acetone and its co-product 4-hydroxy-4-methyl-5-hexen-1-al (or 217 ethenyl-2-methyl-5-hydroxytetrahydrofuran) by both channels (1) and (2), Figure 9b. The yield of 4-hydroxy-4-methyl-5-hexen-1-al was not quantified, since a reference spectrum of 19 this compound was not available. Its formation yield has been estimated at $(75 \pm 10) \%$ by Lee 20 et al. $^{24},(46 \pm 11) \%$ by Shu et al. ${ }^{3}$ and in the range $18-43 \%$ by Calogirou and Kotzias ${ }^{17}$ in 21 studies performed in the presence of $\mathrm{NO}_{\mathrm{X}}$.

22 Acetone is formed from decomposition of the alkoxy radical generated following addition of $23 \mathrm{OH}$ to either carbon atom of the $\mathrm{R}-\mathrm{CH}=\mathrm{C}\left(\mathrm{CH}_{3}\right)_{2}$ double bond in linalool, while 24 glycolaldehyde is the major product generated by addition of $\mathrm{OH}$ to the $\mathrm{R}-\mathrm{CH}=\mathrm{CH}_{2}$ group, 25 Figures $9 \mathrm{~b}$ and $9 \mathrm{a}$ respectively. Assuming that the peroxy radicals produced in the reaction of 
$1 \mathrm{OH}$ with linalool are quantitatively converted to the corresponding alkoxy radicals, then the

2 ratio of the yields of acetone (34\%) to glycolaldehyde (14\%) of 2.4 represents the relative

3 importance of the addition of $\mathrm{OH}$ to the $\mathrm{R}-\mathrm{CH}=\mathrm{C}\left(\mathrm{CH}_{3}\right)_{2}$ and $\mathrm{R}-\mathrm{CH}=\mathrm{CH}_{2}$ sites in linalool. The

4 kinetic data suggests that the ratio should be about $1.6(59 \%$ / 36\%). However, the relatively

5 low yields for the formation of both acetone and glycoaldehyde indicate that conversion of the

6 peroxy radicals to the corresponding alkoxy radicals by reaction with alkyl peroxy or hydro

7 peroxy radicals is relatively low.

8 Aerosol formation. The relatively rapid reaction of $\mathrm{OH}$ radicals with the unsaturated alcohols

9 means that investigations on SOA formation in these reactions are simplified compared to

10 studies of the corresponding reactions with $\mathrm{O}_{3}$. The photolyses were carried out using only

11 one lamp in order to reduce the influence of UV light on the SOA formation rate, ${ }^{51}$ and to

12 limit the increase of temperature during the reactions which could have an impact on gas-

13 particle partitioning and the chemical mechanism. ${ }^{52-54}$ Under our experimental conditions,

14 SOA formation was observed 5 to 20 minutes after photolysis commenced. Figure 10 shows

15 an example of the particle size distribution over the course of the reaction. Growth of the 16 particles by condensation reaches a maximum, and then decreases due to coagulation and wall 17 loss.

18 The SOA yield from the $\mathrm{OH}$ radical initiated oxidation of 3-methyl-1-penten-3-ol was in the 19 range $0.8-1.5 \%$ under our experimental conditions, while the corresponding reaction of 620 methyl-5-hepten-2-ol led to a SOA formation yield of 0.2-0.8\%. Experiments carried out on 21 the oxidation of linalool led to SOA formation yields ranging from 14 to 52\%. Thus, 22 formation of SOA from the oxidation of linalool is considerably more efficient than for the 23 other two unsaturated alcohols investigated. It is of interest to compare the SOA yield of 0.8$241.5 \%$ obtained for the oxidation of 3-methyl-1-penten-3-ol to that of $\sim 0.1 \%$ reported for the 25 structurally similar molecule 2-methyl-3-buten-2-ol $\left(\left(\mathrm{CH}_{3}\right)_{2} \mathrm{C}(\mathrm{OH}) \mathrm{CH}=\mathrm{CH}_{2}\right) .{ }^{55}$ Previous 
1 studies on SOA formation from the $\mathrm{OH}$-initiated oxidation of linalool have been carried out in

2 the presence of $\mathrm{NO}_{\mathrm{X}}$, and the reported mass yields were in the range 4 to $18 \%{ }^{18,20,24,25}$ These

3 yields are considerably lower than found in this work, however, the SOA mass yields

4 obtained from $\mathrm{NO}_{\mathrm{X}}$-free experiments has been found to be significantly higher than in

5 experiments conducted in the presence of $\mathrm{NO}_{\mathrm{X}}$. For example, a $\mathrm{NO}_{\mathrm{X}}$-dependence for $\mathrm{SOA}$

6 formation has previously been observed for the OH-initiated reaction of isoprene $\mathrm{s}^{56}$ and $\alpha$ -

7 pinene. ${ }^{57}$ It has been suggested that for low $\mathrm{NO}_{\mathrm{X}}$-conditions, peroxy radicals will react with

$8 \mathrm{RO}_{2}$ or $\mathrm{HO}_{2}$ radicals rather than $\mathrm{NO}$, leading to formation of organic acids with low volatilities

9 which will increase SOA mass yields. ${ }^{58}$

\section{5. Atmospheric implications}

12 The rate coefficients obtained in this study for the reactions of three unsaturated alcohols with 13 ozone and $\mathrm{OH}$ radicals can be used to estimate their tropospheric lifetimes with respect to 14 reaction with these oxidants. Using the 24 hour average atmospheric concentration of ozone, $157 \times 10^{11}$ molecule $\mathrm{cm}^{-3},{ }^{59}$ and the 12 hour daytime average concentration of $\mathrm{OH}$ radicals, $2 \times$ $1610^{6}$ molecule $\mathrm{cm}^{-3},{ }^{60}$ the calculated lifetimes due to reaction with $\mathrm{OH}$ radicals are: $49 \mathrm{~min}, 1.4$ 17 hours and 2.2 hours for linalool, 6-methyl-5-hepten-2-ol and 3-methyl-1-penten-3-ol 18 respectively, while those due to reaction with ozone are: $58 \mathrm{~min}, 1.1$ hours and 3 days for 19 linalool, 6-methyl-5-hepten-2-ol and 3-methyl-1-penten-3-ol respectively. Hence, linalool, 620 methyl-5-hepten-2-ol and 3-methyl-1-penten-3-ol have relatively short lifetimes and will be 21 degraded close to their emission sources. Long-range transport of these compounds will be of 22 little importance. The atmospheric degradation of unsaturated alcohols by reaction with $\mathrm{OH}$ 23 radicals and ozone will lead to formation of various carbonyl compounds, which may 24 influence the composition of the lower troposphere. Low molecular weight carbonyl 25 compounds such as acetone, formaldehyde, hydroxyacetone and glycolaldehyde will be 
1 degraded by photolysis and reaction with $\mathrm{OH}$ radicals with atmospheric lifetimes estimated

2 from a few hours to a few days. ${ }^{61-64}$ Acetone has been recognized as a source of $\mathrm{HO}_{\mathrm{X}}$ in the 3 upper troposphere and may have an effect on the stratospheric ozone budget. ${ }^{61}$

4 Hydroxyacetone and glycolaldehyde have been detected in both gas and particulate phases in

5 various forest environments, and it is likely that a significant fraction of these compounds 6 might arise through the degradation of BVOCs. ${ }^{65}$

7 In general, the three unsaturated alcohols investigated in this work are unlikely to make a 8 significant contribution to SOA formation in the atmosphere through reaction with ozone or $9 \mathrm{OH}$ radicals. However, it is possible that the reaction of linalool with $\mathrm{OH}$ under low $\mathrm{NO}_{\mathrm{X}}$ 10 conditions close to emission sources such as forested areas could constitute a source of 11 condensed organic material that might be rapidly produced due to the high reactivity of 12 linalool. A detailed examination of SOA formation from the $\mathrm{OH}$-initiated oxidation of 13 linalool as a function of $\mathrm{NO}_{\mathrm{X}}$ under atmospheric conditions would be of interest.

\section{Associated Content}

16 Data obtained in the absolute measurements of the reaction of ozone with the studied alcohols 17 and the SOA formation yield from the ozone and $\mathrm{OH}$ reactions are attached. $\mathrm{O}_{3}$ - and $\mathrm{OH}-$ 18 initiated gas phase oxidation mechanisms are also included. Plots of the gas phase oxidation 19 products from the ozonolysis reaction of linalool and the SOA mass concentration versus the 20 time from the $\mathrm{OH}$ reaction with linalool are showed. This material is available free of charge 21 via the Internet at http://pubs.acs.org.

\section{Acknowledgments}


1 This work was supported by EUROCHAMP 2, the Labex VOLTAIRE and the French

2 Program of Atmospheric Chemistry (CHAT-LEFE) of CNRS. We also thank the staff of 3 CEAM for their assistance for the EUPHORE chamber experiments. 


\section{References}

2

3

4 York, 2011

5

6 7

8

9

10 4128-4133. 2659.

(1) Calvert, J. G.; Mellouki, A.; Orlando, J. J.; Pilling, M. J.; Wallington, T. J. The mechanisms of atmospheric oxidation of the oxygenates; Oxford University Press Inc: New

(2) Grosjean, E.; Grosjean, D. J. Atmos. Chem. 1997, 27, 271-289.

(3) Shu, Y.; Kwok, E. S. C; Tuazon, E. C.; Atkinson, R.; J. Arey, J.. Environ. Sci. Technol. 1997, 31, 896-904.

(4) Grosjean, E.; Grosjean, D. J. Atmos. Chem. 1999, 32, 205-232.

(5) Noda, J.; Ljungström, E. Atmos. Environ. 2002, 36, 521-525.

(6) Noda, J.; Nyman, G.; Langer, S. J. Phys. Chem. A 2002, 106, 945-951.

(7) Atkinson, R.; Arey, J. Atmos. Environ. 2003, 37, S197-S219.

(8) Noe, S. M.; Ciccioli, P.; Brancaleoni, E.; Loreto, F.; Niinemets, Ü. Atmos. Environ. 2006, 40, 4649-4662.

(9) Simon, V.; Dumergues L.; Solignac, G.; Torres, L. Atmos. Res. 2005, 74, 37-48.

(10) Arey, J.; Corchnoy, S. B.; Atkinson, R. Atmos. Environ. 1991, 25, 1377-1381.

(11) Bouvier-Brown, N. C.; Goldstein, A. H.; Gilman, J. B.; Kuster, W. C.; de Gouw, J. A. Atmos. Chem. Phys. 2009, 9, 5505-5518.

(12) Aubert, C.; Chanforan, C. J. Agric. Food Chem. 2007, 55, 3074-3082.

(13) Werkhoff, P.; Güntert, M.; Krammer, G.; Sommer, H.; Kaulen, J. J. Agric. Food Chem. 1998, 46, 1076-1093.

(14) Malowicki, S. M. M.; Martin, R.; Qian M. C. J. Agric. Food Chem. 2008, 56,

(15) Kidambi, S.; Dai, J.; Li, J.; Bruening, M. L. J. Am. Chem. Soc. 2004, 126, 2658- 
(16) Atkinson, R.; Arey, J.; Aschmann, S. M.; Corchnoy, S. B.; Shu, Y. Int. J. Chem.

2 Kinet. 1995, 27, 941-955.

3

4

(17) Calogirou, A.; Kotzias, D. Naturwissenschaften 1995, 82, 288-289.

(18) Hoffmann, T.; Odum, J. R.; Bowman, F.; Collins, D.; Klockow, D.; Flagan, R. C.;

Seinfeld, J. H J. Atmos. Chem. 1997, 26, 189-222.

(19) Grosjean, E.; Grosjean, D. Int. J. Chem. Kinet. 1998, 30, 21-29.

(20) Griffin, R. J.; Cocker III, D. R.; Flagan, R. C.; Seinfeld, J. H. J. Geophys. Res. 1999, $104,3555-3567$.

(21) Bernhard, M. J.; Simonich, S. L. Environ. Chem. 2000, 19, 1705-1710.

(22) Aschmann, S. M.; Arey, J.; Atkinson, R. Atmos. Environ. 2002, 36, 4347-4355.

(23) Lee, A.; Goldstein, A. H.; Keywood, M. D.; Gao, S.; Varutbangkul, V.; Bahreini, R.; N.; Ng, L.; Flagan, R. C.; Seinfeld, J. H. J. Geophys. Res. 2006, 111, D07302, 1-18.

(24) Lee, A.; Goldstein, A. H.; Kroll, J. H.; Ng, N. L.; Varutbangkul, V.; Flagan, R. C.; Seinfeld, J. H. J. Geophys. Res. 2006, 111, D17305, 1-25.

(25) Varutbangkul, V.; Brechtel, F. J.; Bahreini, R.; Ng, N. L.; Keywood, M. D.; Kroll, J. H.; Flagan, R. C.; Seinfeld, J. H.; Lee, A.; Goldstein, A. H. Atmos. Chem. Phys. 2006, 6, 2367-2388.

(26) Chen, X.; Hopke, P. K. Atmos. Environ. 2009, 43, 3935-3940.

(27) Bernard, F.; Eyglunent, G.; Daële, V.; Mellouki, A. J. Phys. Chem. A 2010, 114, $8376-8383$.

(28) The European Photoreactor EUPHORE; Final Report of the EC-Project, Contract EV5V-CT92-0059; Becker, K. H., Ed.; Wuppertal, Germany, 1996.

(29) Klotz, B.; S. Sørensen, S.; Barnes, I.; Becker, K. H.; Etzkorn, T.; Volkamer, R.; Platt, U.; Wirtz, K.; Martín-Reviejo, M. J. Phys. Chem. A 1998, 102, 10289-10299. 
(30) Klotz, B.; Graedler, F.; Sørensen, S.; Barnes, I.; Becker, K. H. Int. J. Chem. Kinet.

2 2001, 33, 9-20.

3

4

(31) Martín-Reviejo, M.; Wirtz, K. Environ. Sci. Technol. 2005, 39, 1045-1054.

(32) Atkinson, R. Atmos. Chem. Phys. 2003, 3, 2233-2307.

(33) Atkinson, R.; Baulch, D. L.; Cox, R. A.; Crowley, J. N.; Hampson, R. F.; Hynes,

R. G.; Jenkin, M. E.; Rossi, M. J.; Troe, J. Atmos. Chem. Phys. 2006, 6, 3625-4055.

(34) Mellouki, A. Atmospheric fate of unsaturated ethers. Proceedings of the NATO

Advanced Research Workshop on Environmental Simulation Chambers: Application to Atmospheric Chemical Processes, Zakopane, Poland, October 1-4, 2004, Barnes , I., Rudzinski,, K. J., Eds; NATO Science Series: IV, 2006; pp 163-169 (Earth and Environmental Sciences, v 62).

(35) Atkinson R.; Aschmann, S. M. Environ. Sci. Technol. 1993, 27, 1357-1363.

(36) Calvert, J. G.; Atkinson, R.; Kerr, J. A.; Madronich, S.; Moortgat, G. K.;

Wallington, T. J.; Yarwood, G. The mechanisms of atmospheric oxidation of the alkenes;

Oxford University Press Inc: New York, 2000.

(37) Horie, O.; Moortgat, G. K. Atmos. Environ. 1991, 25A, 1881-1896.

(38) Neeb, P.; Osamu, H.; Moortgat, G. K J. Phys. Chem. A 1998, 102, 6778-6785.

(39) Niki, H.; Maker, P. D.; Savage, C. M.; Breitenbach, L. P.; Hurley, M. D. J. Phys.

Chem. 1987, 91, 941-946.

(40) Martinez, R. I.; Herron, J. T. J. Phys. Chem. 1987, 91, 946-953.

(41) Docherty, K. S; Ziemann, P. J. Aerosol Sci. Technol. 2003, 37, 877-891.

(42) Keywood, M. D.; Kroll, J. H.; Varutbangkul, V.; Bahreini, R.; Flagan, R. C.; Seinfeld, J. H. Environ. Sci. Technol. 2004, 38, 3343-3350.

(43) Jonsson, Å.; Hallquist, M.; Ljungström, E. Environ. Sci. Technol. 2008, 42, 59385944. 
(44) Thiault, G.; Mellouki, A. Atmos. Environ. 2006, 40, 5566-5573.

(45) Cometto, P. M.; Dalmasso, P. R.; Taccone, R. A.; Lane, S. I.; Oussar, F.; Daële, V.; Mellouki, A.; Le Bras, G. J. Phys. Chem. A 2008, 112, 4444-4450.

(46) Calvert, J. G.; Atkinson, R.; Becker, K. H.; Kamens, R. M.; Seinfeld, J. H.;

Wallington, T. J.; Yarwood, G. The Mechanisms of Atmospheric Oxidation of the Aromatic Hydrocarbons; Oxford University Press Inc: New York, 2002.

(47) Kwok, E. S. C.; Atkinson, R. Atmos. Environ. 1995, 29, 1685-1695.

(48) Bethel, H. L.; Atkinson, R.; Arey, J. Int. J. Chem. Kinet. 2001, 33, 310-316.

(49) Smith, A. M.; Rigler, E.; Kwok, E. S. C.; Atkinson, R. Environ. Sci. Technol. 1996, 30, 1781-1785.

(50) Atkinson, R.; Aschmann, S. M.; Carter, W. P. L.; Winer, A. M.; Pitts, J. N. J. J. Phys. Chem. 1982, 86, 4563-4569.

(51) Presto, A. A.; Huff Hartz, K. E.; Donahue, N. M. Environ. Sci. Technol. 2005, 39, 7036-7045.

(52) Pathak, R. K.; Presto, A. A.; Lane, T. E.; Stanier, C. O.; Donahue, N. M.; Pandis, S. N. Atmos. Chem. Phys. 2007, 7, 3811-3821.

(53) Jonsson, Ä.; Hallquist, M.; Ljungström, E. Atmos. Chem. Phys. 2008, 8, 65416549.

(54) Saathoff, H.; Naumann, K. H.; Möhler, O.; Jonsson, Å. M.; Hallquist, M.; Kiendler-Scharr, A.; Mentel, T. F.; Tillmann, R. ; Schurath, U. Atmos. Chem. Phys. 2009, 9, $1551-1577$.

(55) Chan, A. W. H.; Galloway, M. M.; Kwan, A. J.; Chhabra, P. S.; Keutsch, F. N.; Wennberg, P. O.; Flagan, R. C.; Seinfeld, J. H. Environ. Sci. Technol. 2009, 43, 4647-4652. (56) Kroll, J. H.; Ng, N. L.; Murphy, S. M.; Flagan, R. C.; Seinfeld, J. H. Environ. Sci. Technol. 2006, 40, 1869-1877. 
(57) Ng, N. L.; Chhabra, P. S.; Chan, A. W. H.; Surratt, J. D.; Kroll, J. H.; Kwan, A. J.;

2 McCabe, D. C.; Wennberg, P. O.; Sorooshian, A.; Murphy, S. M. et al. Atmos. Chem. Phys. $3 \quad 2007,7,5159-5174$.

4

(58) Presto, A. A.; Huff Hartz, K. E.; Donahue, N. M. Environ. Sci. Technol. 2005, 39, 5 7036-7045.

6

7

8

9

10

11

12

13

14

15

16

17

18

(59) Logan, J. A. J. Geophys. Res. 1985, 90, 10463-10482.

(60) Hein, R.; Crutzen, P. J.; Heimann, M. Global Biogeochemistry Cycles 1997, 11, 43-76.

(61) Singh, H. B.; O'Hara, D.; Herlth, D.; Sachse, W.; Blake, D. R.; Bradshaw, J. D.; Kanakidou, M.; Crutzen, P. J. J. Geophys. Res. 1994, 99, 1805-1820.

(62) Orlando, J. J.; Tyndall, G. S.; Fracheboud, J.-M.; Estupiñan, E. G.; Haberkorn, S.; Zimmer, A. Atmos. Environ. 1999, 33, 1621-1629.

(63) Bacher, C.; Tyndall, G. S.; Orlando, J. J. J. Atmos. Chem. 2001, 39, 171-189.

(64) Possanzini M.; Di Palo, V.; Cecinato, A. Atmos. Environ., 2002, 36, 3195-3201.

(65) Matsunaga, S. N.; Wiedinmyer, C.; Guenther, A. B.; Orlando, J. J.; Karl, T.; 
Table 1. Reactions with $\mathrm{O}_{3}$, Relative rate method: summary of the experimental conditions, 2 and results obtained at room temperature in 760 Torr of purified air and in the presence of an 3 excess of cyclohexane.

\begin{tabular}{|c|c|c|c|c|c|}
\hline Alcohols & Reference & $\begin{array}{c}\mathrm{N}^{\circ} \\
\text { of runs }\end{array}$ & $\mathrm{T}(\mathrm{K})$ & $\left(k / k_{\text {Ref. }} \pm 1 \sigma\right)$ & $\begin{array}{c}(k \pm 1 \sigma) \\
\left(\mathrm{cm}^{3} \text { molecule }^{-1} \mathrm{~s}^{-1}\right)\end{array}$ \\
\hline \multirow[t]{3}{*}{ linalool } & butyl vinyl ether & 2 & $295.0 \pm 0.3$ & $1.38 \pm 0.07$ & $(4.0 \pm 0.5) \times 10^{-16}$ \\
\hline & propyl vinyl ether & 1 & $295.7 \pm 0.1$ & $1.77 \pm 0.04$ & $(4.3 \pm 0.8) \times 10^{-16}$ \\
\hline & & & \multicolumn{3}{|c|}{$k=(4.1 \pm 1.0) \times 10^{-16} \mathrm{~cm}^{3}$ molecule $^{-1} \mathrm{~s}^{-1}$} \\
\hline \multirow{3}{*}{$\begin{array}{l}\text { 6-methyl-5- } \\
\text { hepten-2-ol }\end{array}$} & butyl vinyl ether & 2 & $300.9 \pm 0.3$ & $1.41 \pm 0.08$ & $(4.1 \pm 0.5) \times 10^{-16}$ \\
\hline & propyl vinyl ether & 2 & $301.8 \pm 0.1$ & $1.39 \pm 0.10$ & $(3.3 \pm 0.8) \times 10^{-16}$ \\
\hline & & & \multicolumn{3}{|c|}{$k=(3.7 \pm 1.2) \times 10^{-16} \mathrm{~cm}^{3}$ molecule $\mathrm{e}^{-1} \mathrm{~s}^{-1}$} \\
\hline \multirow{2}{*}{$\begin{array}{l}\text { 3-methyl-1- } \\
\text { penten-3-ol }\end{array}$} & propene & 3 & $294 \pm 2$ & $0.50 \pm 0.01$ & $(5.0 \pm 0.6) \times 10^{-18}$ \\
\hline & & & \multicolumn{3}{|c|}{$k=(5.0 \pm 0.6) \times 10^{-18} \mathrm{~cm}^{3}$ molecule $\mathrm{e}^{-1} \mathrm{~s}^{-1}$} \\
\hline
\end{tabular}


Table 2a. Reaction of linalool with $\mathrm{O}_{3}$ : gas phase product yields (Cyclohexane used as $\mathrm{OH}$ scavenger).

\begin{tabular}{|l|c|}
\hline linalool $+\mathrm{O}_{3}$ & \\
\hline Acetone & $35 \pm 6$ \\
\hline Formaldehyde & $32 \pm 6$ \\
\hline Hydroxyacetone & $28 \pm 5$ \\
\hline Carbon balance & $22 \pm 4$ \\
\hline & \\
\hline
\end{tabular}

Table 2b. Reaction of 6-methyl-5-hepten-2-ol with $\mathrm{O}_{3}$ : gas phase product yields (Cyclohexane used as $\mathrm{OH}$ scavenger).

\begin{tabular}{|l|c|}
\hline 6-methyl-5-hepten-2-ol $+\mathrm{O}_{3}$ & \\
\hline & $31 \pm 7$ \\
\hline Acetone $^{\mathrm{a}, \mathrm{b}}$ & $40 \pm 10$ \\
\hline Formaldehyde $^{\mathrm{a}}$ & $17 \pm 2$ \\
\hline Hydroxyacetone $^{\mathrm{a}}$ & $16 \pm 4$ \\
\hline Formic acid $^{\mathrm{a}}$ & $10 \pm 1$ \\
\hline Methylglyoxal $^{\mathrm{c}, \mathrm{d}}$ & $34 \pm 11$ \\
\hline 4-hydroxypentanal & $\mathrm{d}, \mathrm{e}$ \\
\hline Carbon balance & $50 \pm 12$ \\
\hline
\end{tabular}

${ }^{\mathrm{a}}$ Obtained from FT-IR analysis.

${ }^{\mathrm{b}}$ Obtained from GC-PID analysis.

${ }^{\mathrm{c}}$ Obtained from GC-ECD analysis.

${ }^{\mathrm{d}}$ Yields of identified products measured by HPLC-UV and by GC-ECD are obtained by the consumption of 6-methyl-5-hepten-2-ol by GC-MS.

${ }^{\mathrm{e}}$ 4-hydropentanal was quantified using 4-pentanal as a surrogate by HPLC-UV (see text).

Table 2c. Reaction of 3-methyl-1-penten-3-ol with $\mathrm{O}_{3}$ : gas phase product yields (Cyclohexane used as $\mathrm{OH}$ scavenger).

\begin{tabular}{|l|c|}
\hline 3-methyl-1-penten-3-ol $+\mathrm{O}_{3}$ & \\
\hline Formaldehyde & $29 \pm 4$ \\
\hline Carbon monoxide & $8 \pm 1$ \\
\hline 2-Butanone & $46 \pm 3$ \\
\hline Carbon balance & $37 \pm 2$ \\
\hline
\end{tabular}


Table 3. Reactions with $\mathrm{OH}$ radicals, Relative rate method: summary of the experimental conditions, and results obtained at room temperature in 760 Torr of purified air.

\begin{tabular}{|c|c|c|c|c|c|}
\hline Alcohols & Reference & $\begin{array}{c}\mathrm{N}^{\circ} \\
\text { of runs }\end{array}$ & $\mathrm{T}(\mathrm{K})$ & $\left(k / k_{\text {Ref. }} \pm 1 \sigma\right)$ & $\begin{array}{c}(k \pm 1 \sigma) \\
\left(\mathrm{cm}^{3} \text { molecule }_{1}^{-1} \mathrm{~s}^{-}\right. \\
1)\end{array}$ \\
\hline \multirow[t]{3}{*}{ linalool } & butyl vinyl ether & 2 & $298 \pm 1$ & $1.57 \pm 0.05$ & $1.73 \pm 0.21$ \\
\hline & isoprene & 2 & $298 \pm 1$ & $1.61+0.09$ & $1.61 \pm 0.25$ \\
\hline & & & \multicolumn{3}{|c|}{$k=(1.7 \pm 0.3) \times 10^{-10} \mathrm{~cm}^{3}$ molecule ${ }^{-1} \mathrm{~s}^{-1}$} \\
\hline \multirow{4}{*}{$\begin{array}{l}\text { 6-methyl-5- } \\
\text { hepten-2-ol }\end{array}$} & butyl vinyl ether & 2 & $294.9 \pm 0.7$ & $0.97 \pm 0.02$ & $1.07 \pm 0.12$ \\
\hline & cyclohexene & 2 & $293.4 \pm 0.5$ & $1.52 \pm 0.06$ & $1.03 \pm 0.30$ \\
\hline & $\begin{array}{l}\text { 3-methyl-3- } \\
\text { buten-1-ol }\end{array}$ & 2 & $294.8 \pm 0.9$ & $1.05 \pm 0.05$ & $0.99 \pm 0.09$ \\
\hline & & & \multicolumn{3}{|c|}{$k=(1.0 \pm 0.3) \times 10^{-10} \mathrm{~cm}^{3}$ molecule ${ }^{-1} \mathrm{~s}^{-1}$} \\
\hline \multirow{3}{*}{$\begin{array}{l}\text { 3-methyl-1- } \\
\text { penten-3-ol }\end{array}$} & propene & 2 & $296.2 \pm 0.7$ & $2.1 \pm 0.1$ & $0.61 \pm 0.09$ \\
\hline & cyclohexene & 2 & $295.7 \pm 0.7$ & $0.94 \pm 0.03$ & $0.64 \pm 0.18$ \\
\hline & & & \multicolumn{3}{|c|}{$k=(6.2 \pm 1.8) \times 10^{-11} \mathrm{~cm}^{3}$ molecule $^{-1} \mathrm{~s}^{-1}$} \\
\hline & & & & & \\
\hline
\end{tabular}


Table 4a. Reaction of linalool with $\mathrm{OH}$ radicals: gas phase product yields $\left(\mathrm{H}_{2} \mathrm{O}_{2}\right.$ used as $\mathrm{OH}$ precursor).

\begin{tabular}{|l|c|}
\hline linalool $+\mathrm{OH}$ & \\
\hline Acetone & $34 \pm 1$ \\
\hline Glycolaldehyde & $14 \pm 1$ \\
\hline 6-methyl-5-hepten-2-one & $10 \pm 2$ \\
\hline Formic acid & $5 \pm 2$ \\
\hline Formaldehyde & $2.8 \pm 0.4$ \\
\hline Carbon monoxide & $2.1 \pm 0.8$ \\
\hline Carbon balance & $22 \pm 2$ \\
\hline
\end{tabular}

4

5

6

12

13

14

Table 4b. Reaction of 6-methyl-5-hepten-2-ol with $\mathrm{OH}$ radicals: gas phase product yields $\left(\mathrm{H}_{2} \mathrm{O}_{2}\right.$ used as $\mathrm{OH}$ precursor).

\begin{tabular}{|l|c|}
\hline 6-methyl-5-hepten-2-ol $+\mathrm{OH}$ & \\
\hline Acetone & $21 \pm 2$ \\
\hline Formic acid & $4.2 \pm 0.7$ \\
\hline Carbon monoxide & $1.2 \pm 0.6$ \\
\hline Formaldehyde & $0.7 \pm 0.4$ \\
\hline Carbon balance & $8 \pm 1$ \\
\hline
\end{tabular}

Table 4c. Reaction of 3-methyl-1-penten-3-ol with $\mathrm{OH}$ radicals: gas phase product yields $\left(\mathrm{H}_{2} \mathrm{O}_{2}\right.$ used as $\mathrm{OH}$ precursor).

\begin{tabular}{|l|c|}
\hline 3-methyl-1-penten-3-ol $+\mathrm{OH}$ & \\
\hline 2-butanone & $41 \pm 6$ \\
\hline Glycolaldehyde & $30 \pm 4$ \\
\hline Formaldehyde & $9 \pm 4$ \\
\hline Carbon monoxide & $2.5 \pm 0.3$ \\
\hline Formic acid & $2.2 \pm 0.9$ \\
\hline Carbon balance & $40 \pm 6$ \\
\hline
\end{tabular}




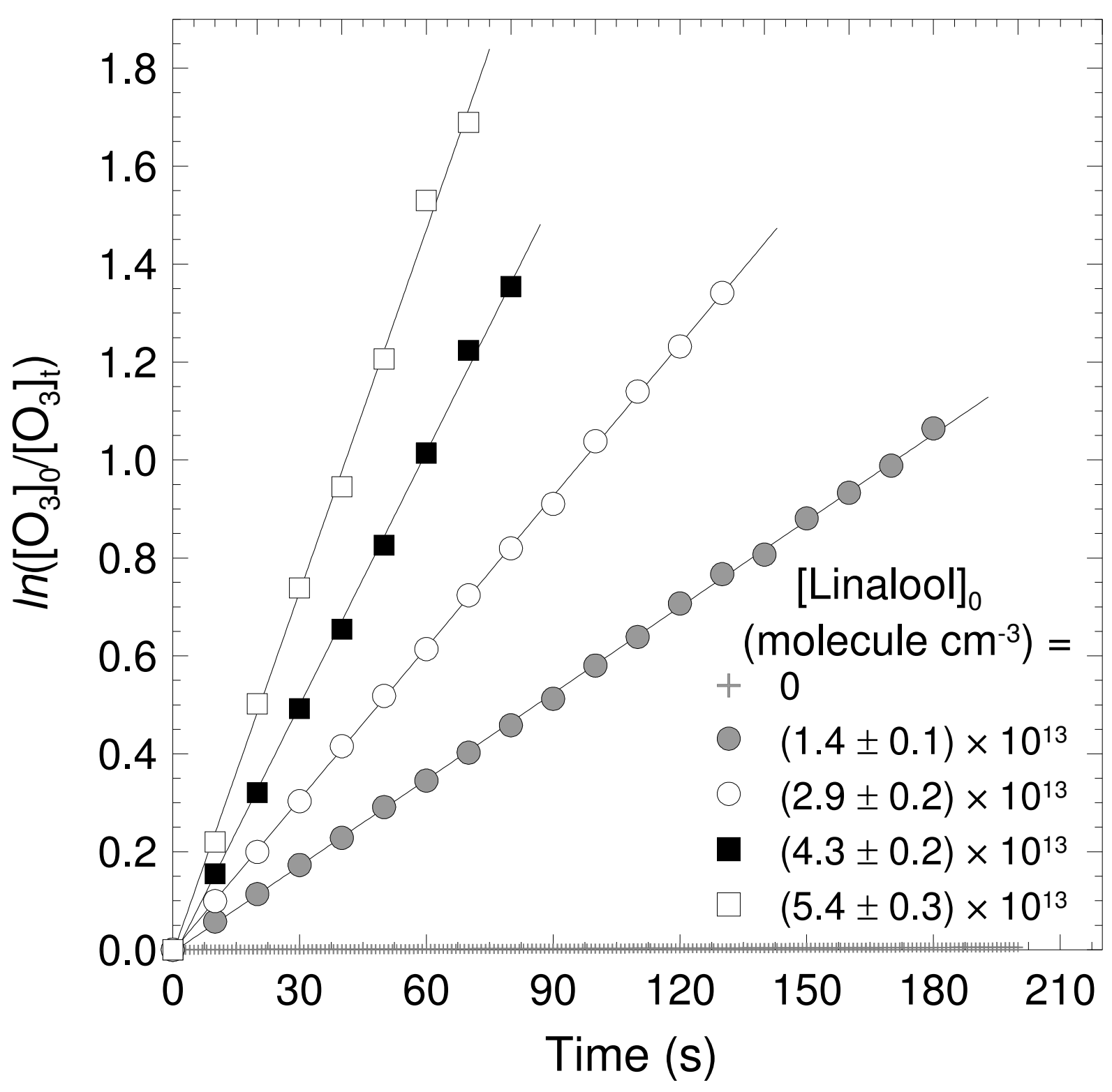

3 Figure 1. Reaction of ozone with linalool (absolute rate method): examples of pseudo-first 4 order ozone decays as a function of reaction time in the presence of different concentrations 5 of linalool. 6 

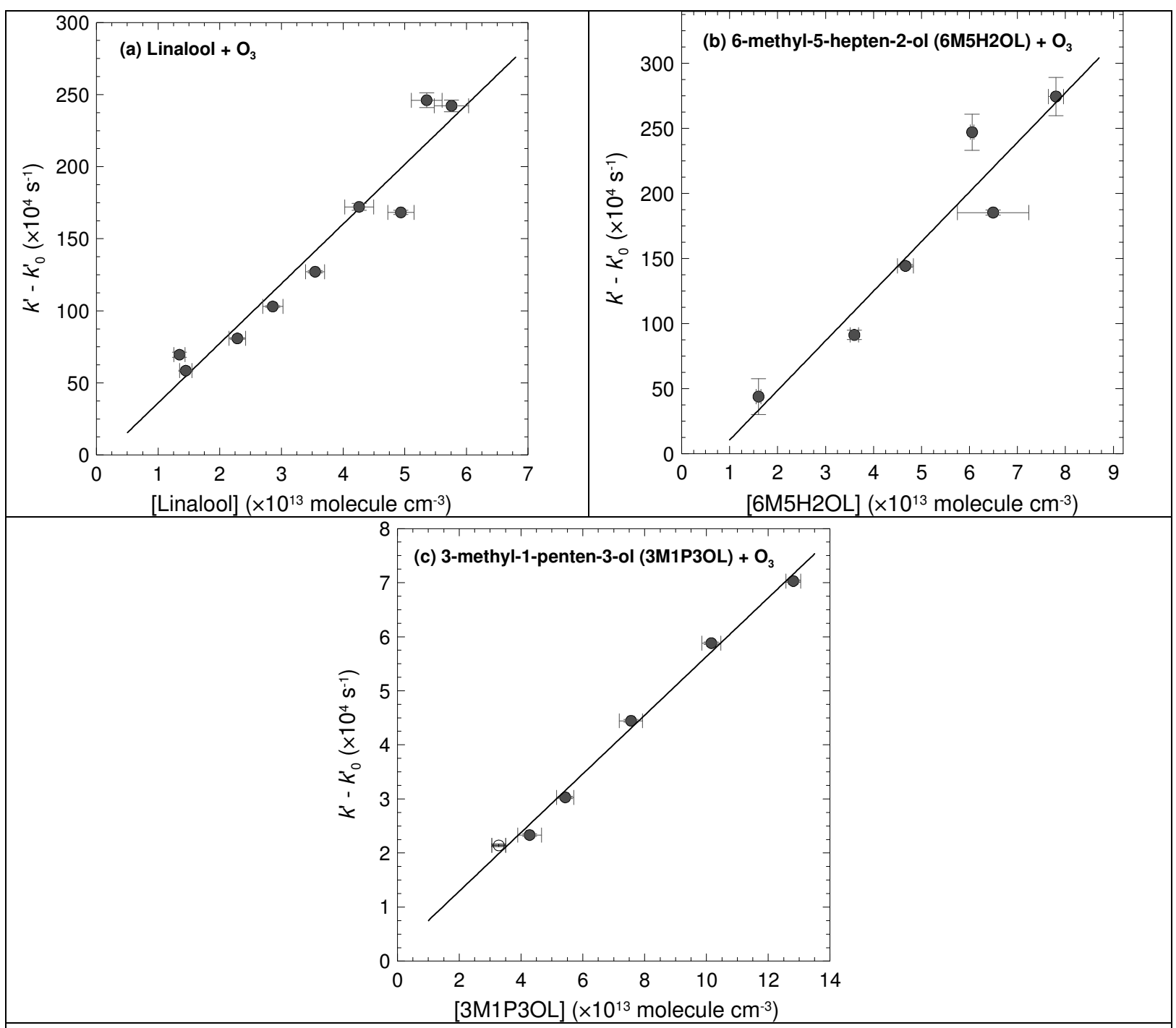

Figure 2. Reaction of $\mathrm{O}_{3}$ with linalool (a), 6-methyl-5-hepten-2-ol (b) and 3-methyl-1-penten3-ol (c): absolute rate kinetic data (Experiments conducted in the presence of an excess of cyclohexane are represented with filled circles while that conducted without cyclohexane is showed with the unfilled symbol). 

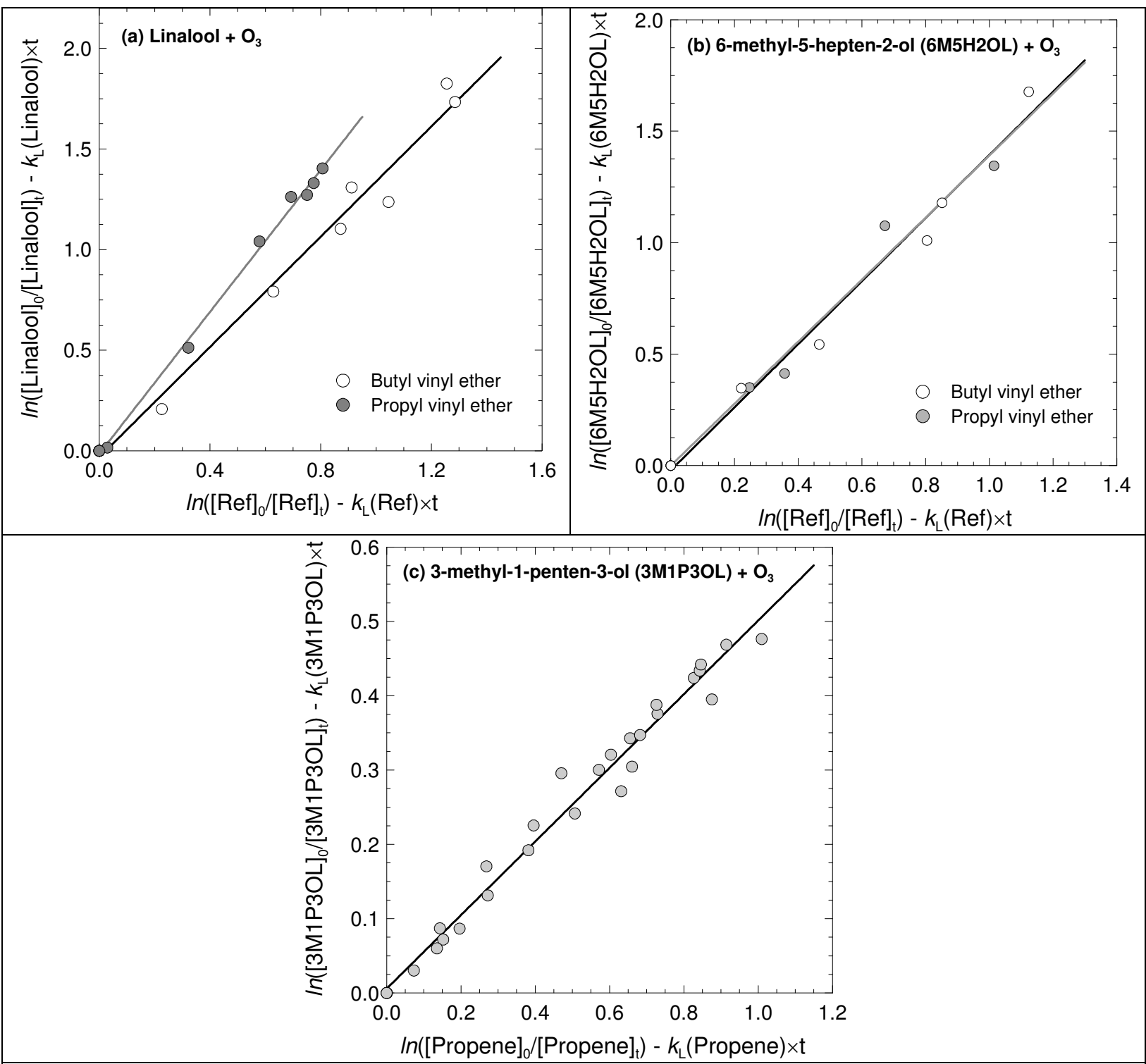

Figure 3. Reaction of $\mathrm{O}_{3}$ with linalool (a), 6-methyl-5-hepten-2-ol (b) and 3-methyl-1-penten3-ol (c): relative rate kinetic data using butyl vinyl ether, propyl vinyl ether and propene as organic references. 2

3 


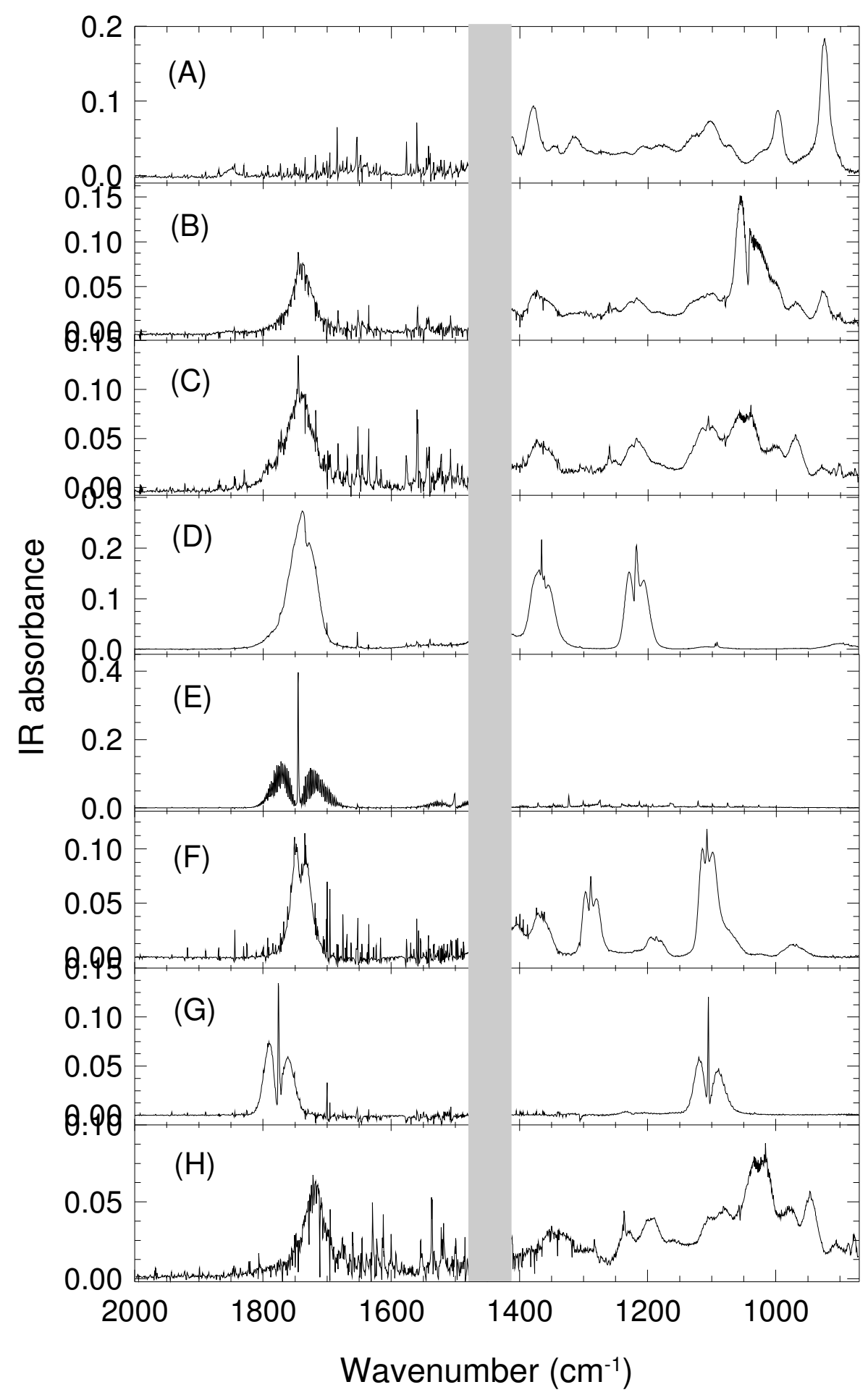

Figure 4. Reaction of linalool with $\mathrm{O}_{3}$ (in the presence of an excess of cyclohexane). Cyclohexane was subtracted from all the IR spectra shown here. Reference IR spectrum of linalool (Panel A), IR spectrum of a mixture of linalool and $\mathrm{O}_{3}$ at the start of the experiment (Panel B), IR spectrum of a mixture of linalool and $\mathrm{O}_{3}$ after 2 hours of reaction (Panel $\mathrm{C}$ ), linalool and $\mathrm{O}_{3}$ are subtracted from the global spectrum); reference IR spectra of acetone (Panel D), formaldehyde (Panel E), hydroxyacetone (Panel F) and formic acid (Panel G); IR residual spectrum after subtraction of reactants (linalool and $\mathrm{O}_{3}$ ) and all identified products (major products: acetone, formaldehyde and hydroxyacetone (and formic acid observed as a secondary minor product) (Panel H). The grey overlap area represents IR band saturation due to the excess of cyclohexane used as $\mathrm{OH}$ scavenger. 


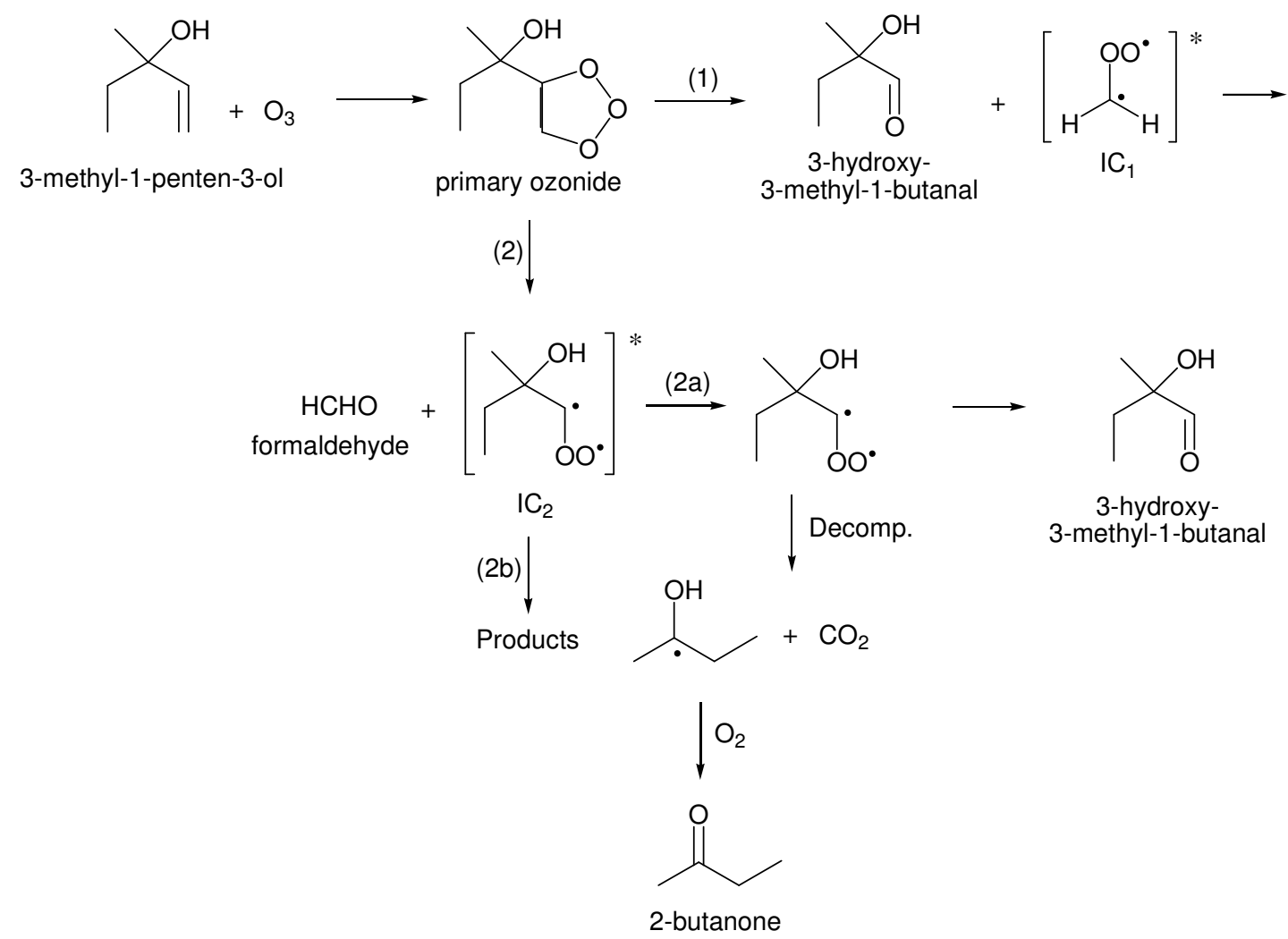

Figure 5. Reaction of 3-methyl-1-penten-3-ol with $\mathrm{O}_{3}$ : proposed mechanism scheme. 


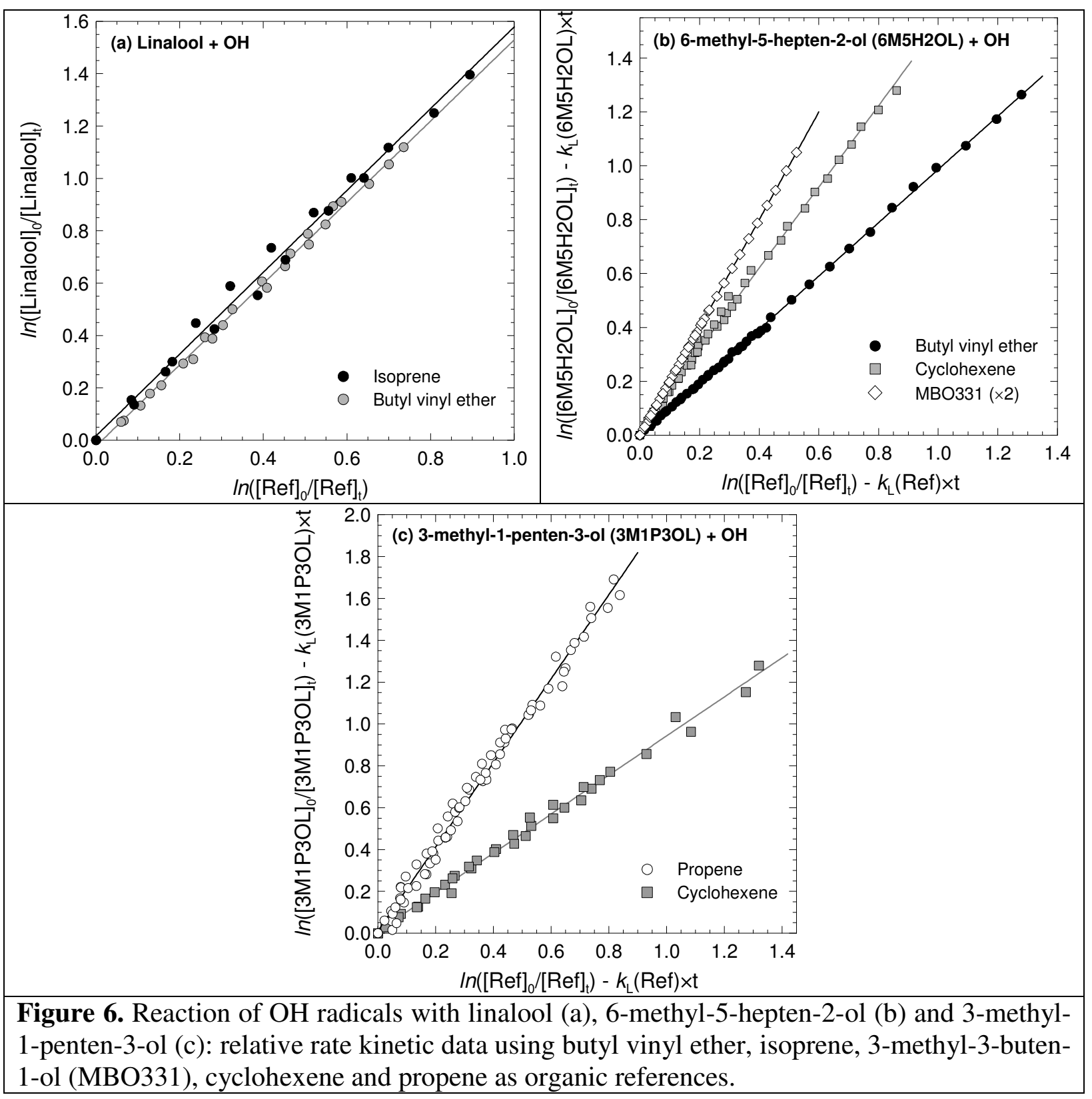




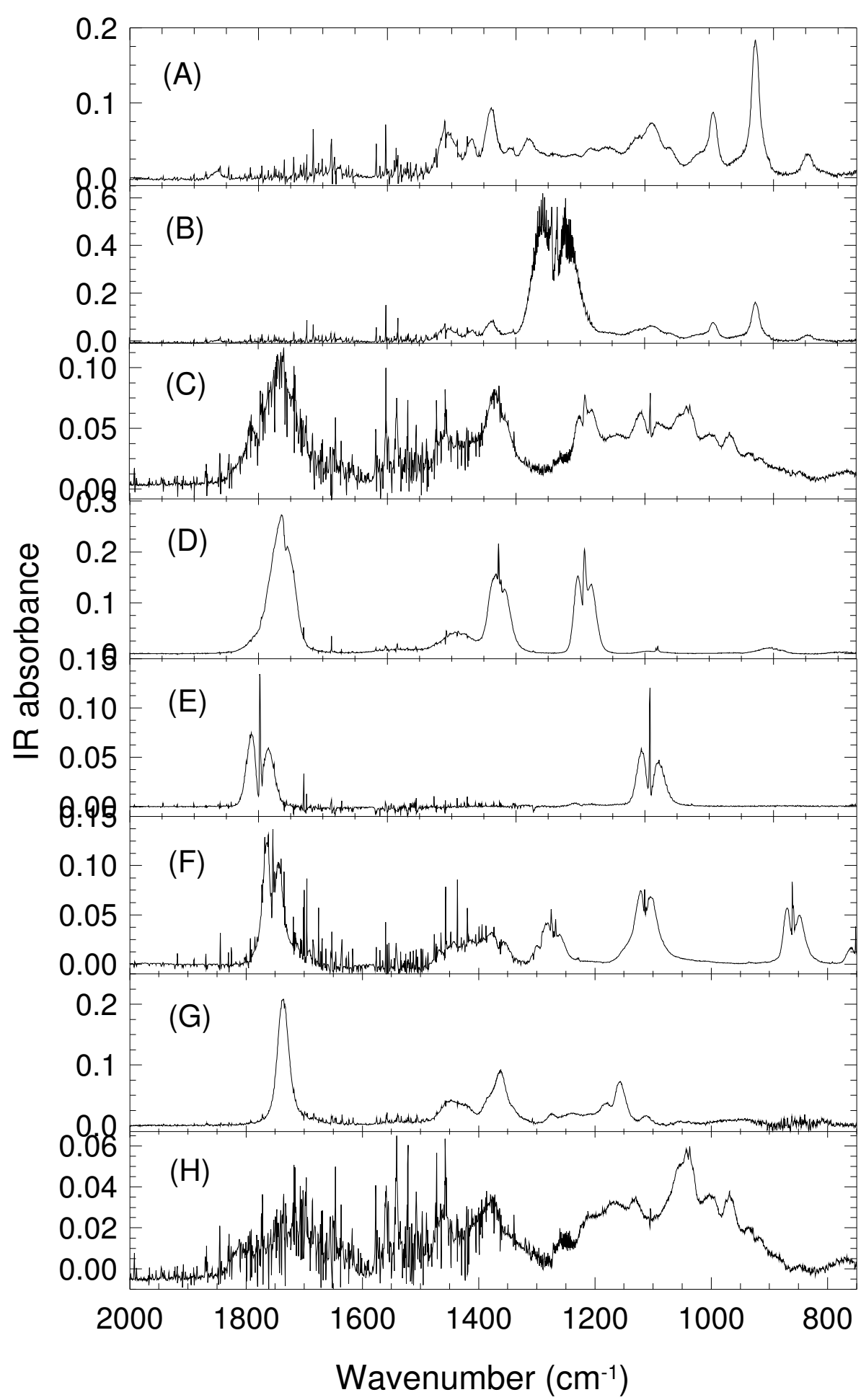

Figure 7. Reaction of linalool with $\mathrm{OH}\left(\mathrm{H}_{2} \mathrm{O}_{2}\right.$ used as $\mathrm{OH}$ precursor): Reference IR spectra of: linalool (Panel A), IR spectrum of mixture linalool and $\mathrm{H}_{2} \mathrm{O}_{2}$ at the start of the experiment (Panel B), IR spectrum of a mixture of linalool and $\mathrm{H}_{2} \mathrm{O}_{2}$ after 4 hours reaction (Panel $\mathrm{C}$ ), linalool and $\mathrm{H}_{2} \mathrm{O}_{2}$ are subtracted from the global spectrum); reference IR spectra of acetone (Panel D), formic acid (Panel E), glycolaldehyde (Panel F) and 6-methyl-5-hepten-2-one (Panel G); IR residual spectrum after subtraction of reactants (linalool and $\mathrm{H}_{2} \mathrm{O}_{2}$ ) and all identified products (major products: acetone, formic acid, glycolaldehyde and 6-methyl-5hepten-2-one) (Panel H). 


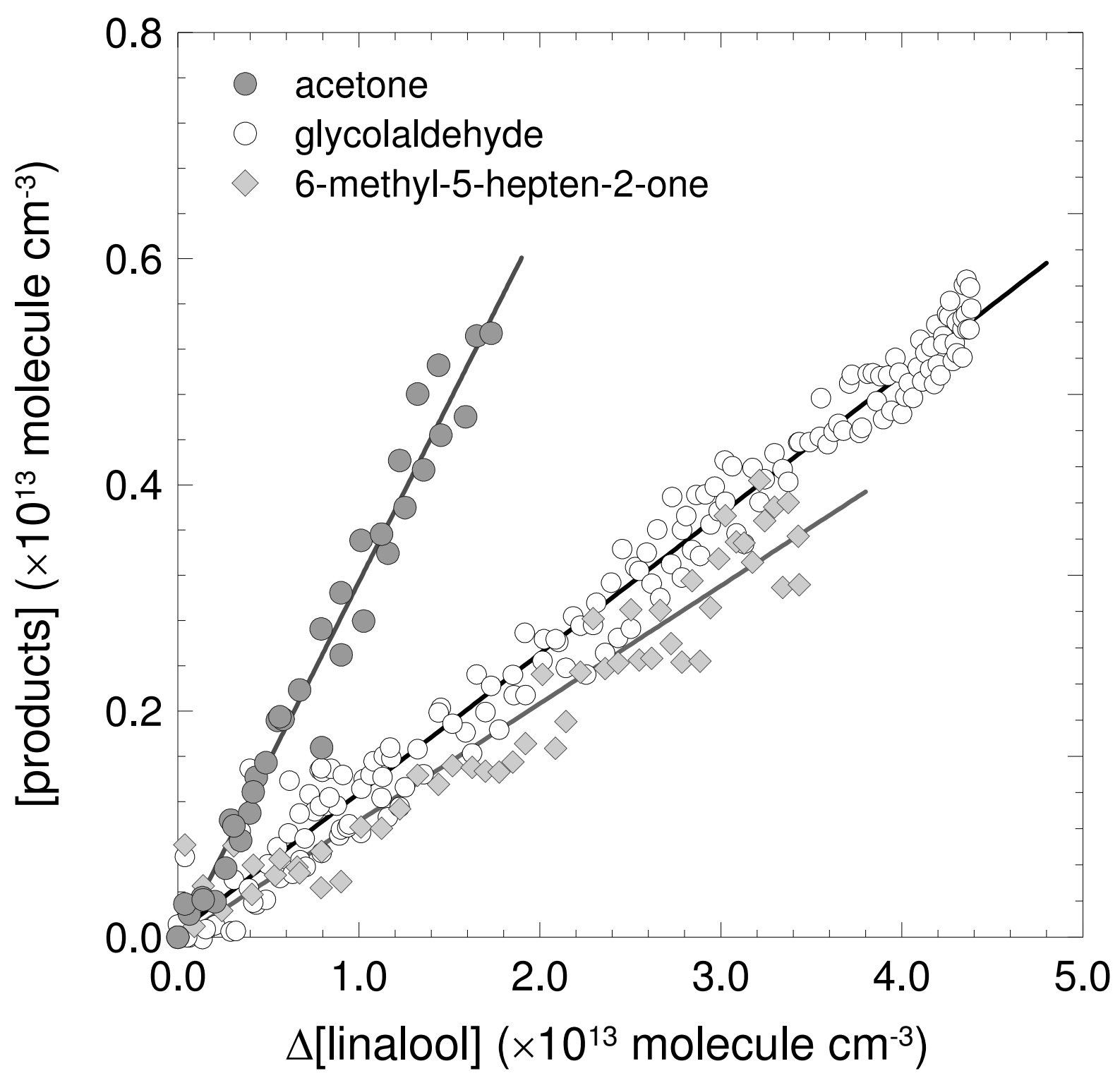

Figure 8. Reaction of linalool with $\mathrm{OH}\left(\mathrm{H}_{2} \mathrm{O}_{2}\right.$ used as $\mathrm{OH}$ precursor): gas phase product yields. 


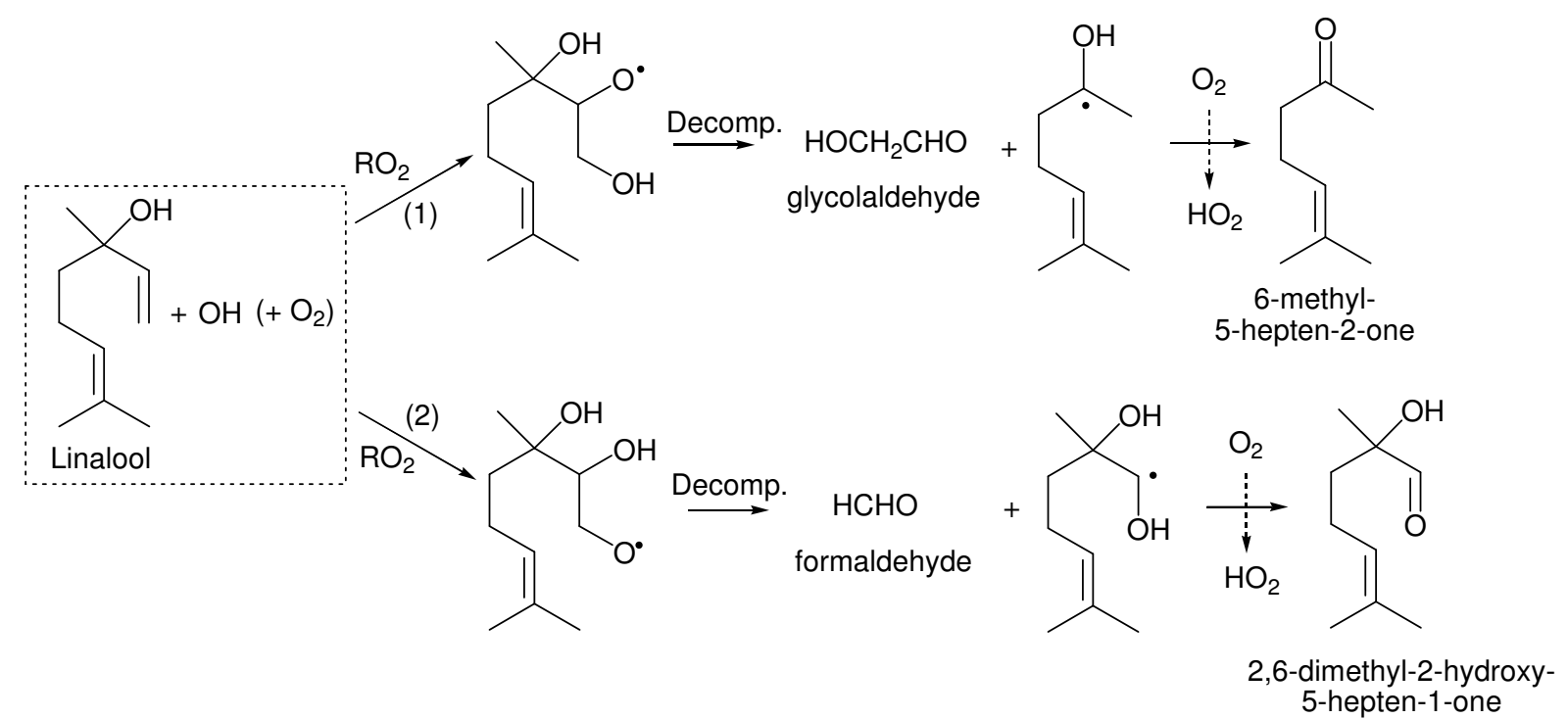

Figure 9a. Reaction of linalool with $\mathrm{OH}$ (in the absence of $\mathrm{NO}_{\mathrm{X}}$ ): proposed mechanism scheme for $\mathrm{OH}$ attack at the $\mathrm{R}-\mathrm{CH}=\mathrm{CH}_{2}$ double bond.

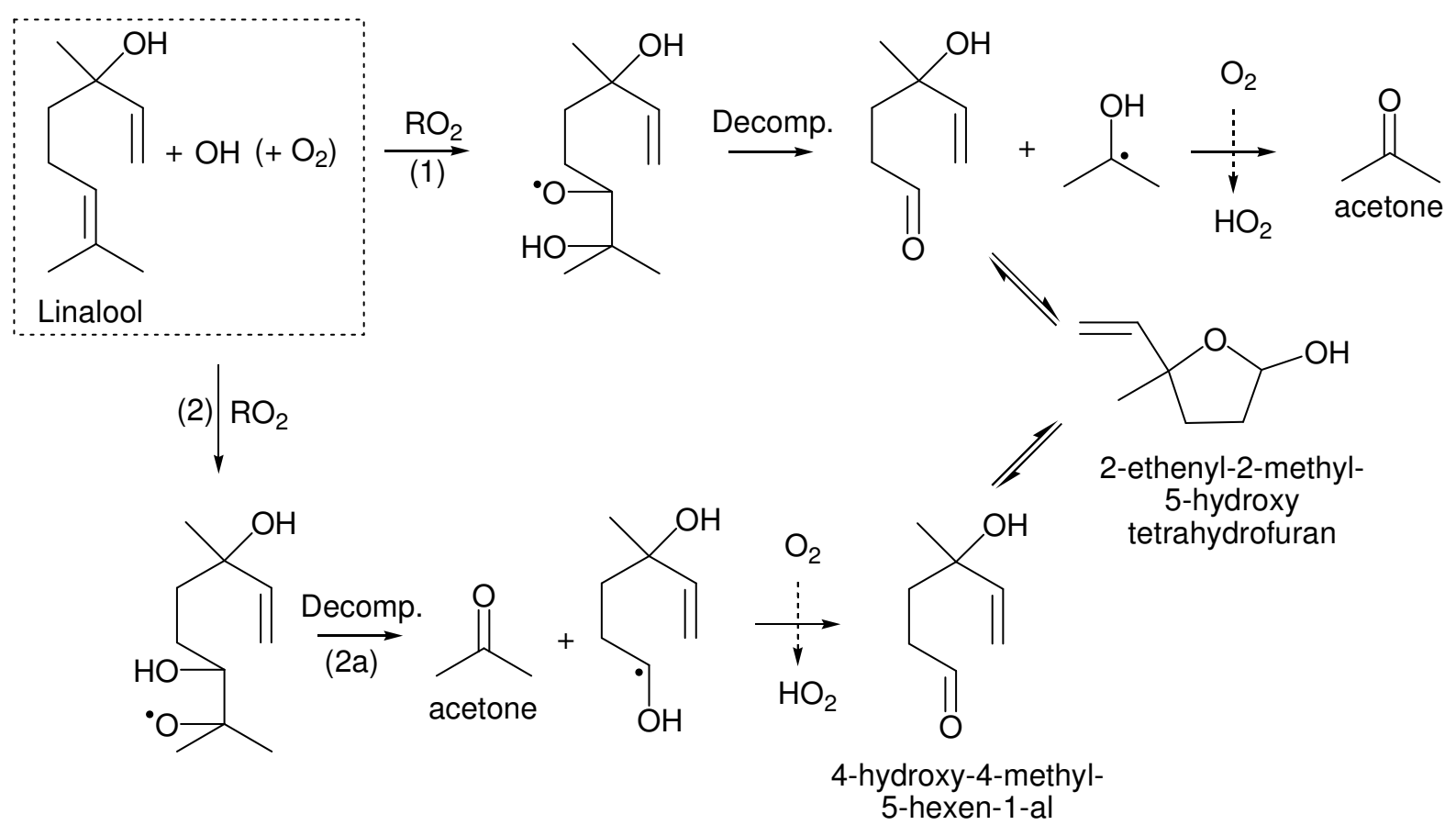

Figure 9b. Reaction of linalool with $\mathrm{OH}$ (in the absence of $\mathrm{NO}_{\mathrm{X}}$ ): proposed mechanism scheme for $\mathrm{OH}$ attack at the $\mathrm{R}-\mathrm{CH}=\mathrm{C}\left(\mathrm{CH}_{3}\right)_{2}$ double bond. 


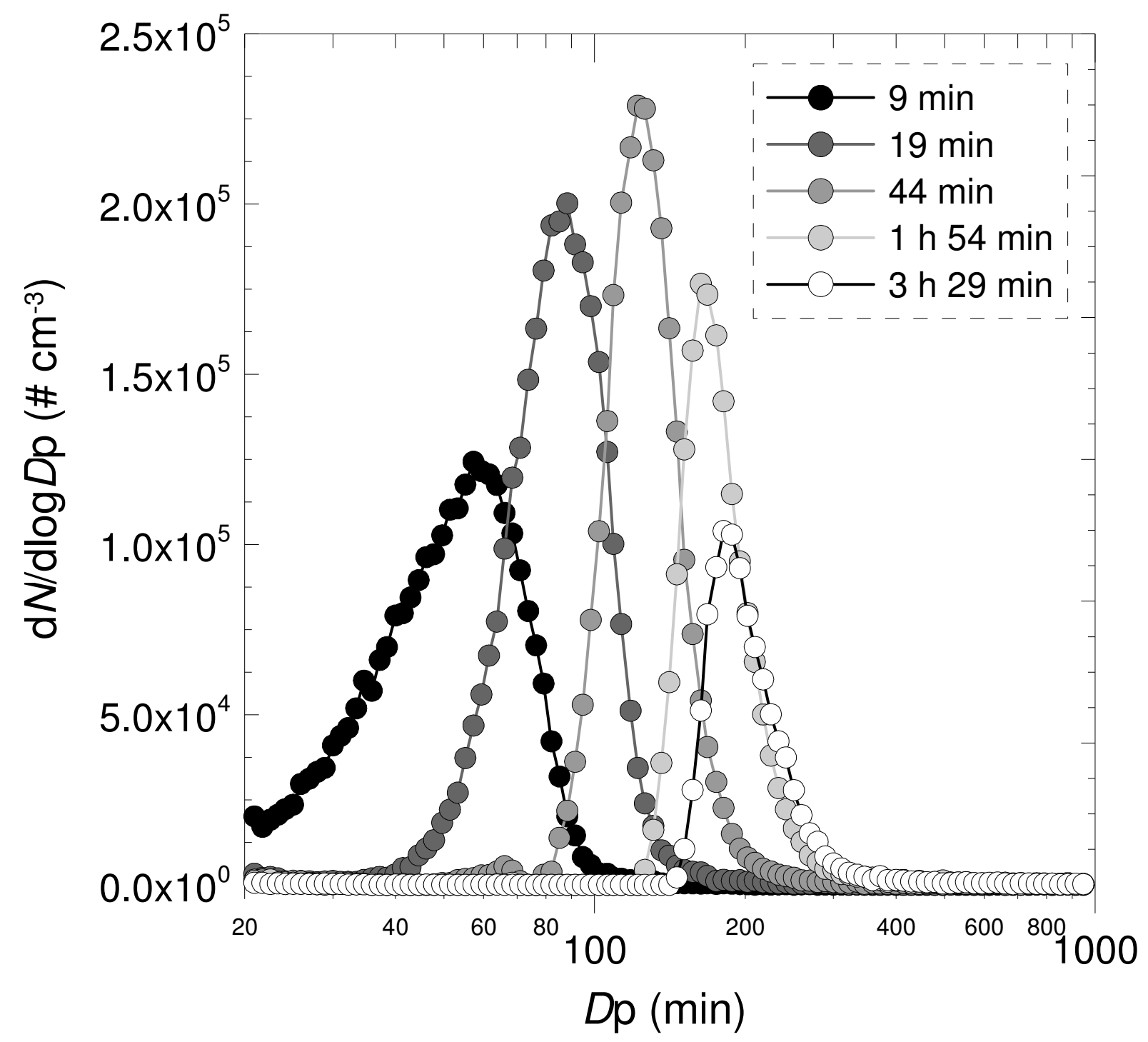

Figure 10. Reaction of linalool with $\mathrm{OH}$ (in the absence of $\mathrm{NO}_{\mathrm{X}}$ ): secondary organic aerosol particle size distribution obtained over the course of the reaction. 
"Table of Contents" Graphic

7

8

9

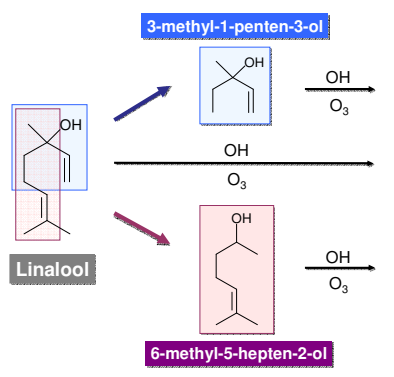

Kinetics 